University of Nebraska - Lincoln

DigitalCommons@University of Nebraska - Lincoln

Public Health Resources

Public Health Resources

2015

\title{
A multicomponent nutrient bar promotes weight loss and improves dyslipidemia and insulin resistance in the overweight/obese: chronic inflammation blunts these improvements
}

Joyce C. McCann

Children's Hospital Oakland Research Institute, jmccann@chori.org

Mark K. Shigenaga

Children's Hospital Oakland Research Institute, mshigenaga@chori.org

Michele L. Mietus-Snyder

Children's Hospital Oakland Research Institute

Ashutosh Lal

Children's Hospital Oakland Research Institute

Jung H. Suh

Children's Hospital Oakland Research Institute

See next page for additional authors

Follow this and additional works at: http://digitalcommons.unl.edu/publichealthresources

McCann, Joyce C.; Shigenaga, Mark K.; Mietus-Snyder, Michele L.; Lal, Ashutosh; Suh, Jung H.; Krauss, Ronald M.; Gildengorin, Ginny L.; Goldrich, Alisa M.; Block, Devan S.; Shenvi, Swapna V.; McHugh, Tara H.; Olson, Don A.; and Ames, Bruce N., "A multicomponent nutrient bar promotes weight loss and improves dyslipidemia and insulin resistance in the overweight/obese: chronic inflammation blunts these improvements" (2015). Public Health Resources. 473.

http://digitalcommons.unl.edu/publichealthresources/473

This Article is brought to you for free and open access by the Public Health Resources at DigitalCommons@University of Nebraska - Lincoln. It has been accepted for inclusion in Public Health Resources by an authorized administrator of DigitalCommons@University of Nebraska - Lincoln. 


\section{Authors}

Joyce C. McCann, Mark K. Shigenaga, Michele L. Mietus-Snyder, Ashutosh Lal, Jung H. Suh, Ronald M. Krauss, Ginny L. Gildengorin, Alisa M. Goldrich, Devan S. Block, Swapna V. Shenvi, Tara H. McHugh, Don A. Olson, and Bruce N. Ames 


\title{
A multicomponent nutrient bar promotes weight loss and improves dyslipidemia and insulin resistance in the overweight/obese: chronic inflammation blunts these improvements
}

\author{
Joyce C. McCann, ${ }^{*, 1}$ Mark K. Shigenaga, ${ }^{, 1}$ Michele L. Mietus-Snyder, ${ }^{*}{ }^{\dagger}$ Ashutosh Lal,* \\ Jung H. Suh, * Ronald M. Krauss, * Ginny L. Gildengorin,* Alisa M. Goldrich,* Devan S. Block, * \\ Swapna V. Shenvi, ${ }^{*}$ Tara H. McHugh, ${ }^{\dagger}$ Don A. Olson, ${ }^{\dagger}$ and Bruce N. Ames* \\ *Nutrition and Metabolism Center, Children's Hospital Oakland Research Institute, Oakland, California, \\ USA; ${ }^{\dagger}$ Children’s National Medical Center, Washington, DC, USA; and ${ }^{\ddagger}$ Processed Foods Research Unit, \\ U.S. Department of Agriculture-Agricultural Research Service-Western Regional Research Center, \\ Albany, California, USA
}

ABSTRACT This study determined if twice-daily consumption of a nutrient-dense bar intended to fill gaps in Western diets, without other dietary/lifestyle requirements, favorably shifted metabolic/anthropometric indicators of dysregulation in a healthy direction. Three 8-wk clinical trials in 43 healthy lean and overweight/obese (OW/OB) adults, who served as their own controls, were pooled for analysis. In less inflamed OW/OB [highsensitivity C-reactive protein (hsCRP) <1.5], statistically significant decreases occurred in weight $(-1.1 \pm 0.5 \mathrm{~kg})$, waist circumference $(-3.1 \pm 1.4 \mathrm{~cm})$, diastolic blood pressure $(-4.1 \pm 1.6 \mathrm{mmHg})$, heart rate $[\mathrm{HR} ;-4.0 \pm 1.7$ beats per minute $(\mathrm{bpm})]$, triglycerides $(-72 \pm 38.2 \mathrm{mg} / \mathrm{dl})$, insulin resistance (homeostatic model of insulin resistance) $(-0.72 \pm 0.3)$, and insulin $(-2.8 \pm 1.3 \mathrm{mU} / \mathrm{L})$; an increase in $\mathrm{HDL}-2 \mathrm{~b}(+303 \pm 116 \mathrm{nM})$ and realignment of LDL lipid subfractions toward a less atherogenic profile [decreased small LDL IIIb $(-44 \pm 23.5 \mathrm{nM})$, LDL IIIa $(-99 \pm 43.7 \mathrm{nM})$, and increased large LDL I $(+66 \pm 28.0 \mathrm{nM})]$. In the more inflamed OW/OB (hsCRP >1.5), inflammation was reduced at 2 wk $(-0.66 \mathrm{mg} / \mathrm{L})$, and $\mathrm{HR}$ at 8 wk (-3.4 $\pm 1.3 \mathrm{bpm})$. The large HDL subfraction $(10.5-14.5 \mathrm{~nm})$ increased at $8 \mathrm{wk}(+346 \pm 126 \mathrm{nM})$. Metabolic improvements were also observed in lean participants. Thus, favorable changes in measures of cardiovascular health, insulin resistance, inflammation, and obesity were initiated within $8 \mathrm{wk}$ in the $\mathrm{OW} / \mathrm{OB}$ by replacing deficiencies in Western diets without requiring other dietary or lifestyle modifications; chronic inflammation blunted most improvements.-McCann, J. C., Shigenaga, M. K., Mietus-Snyder, M. L., Lal, A., Suh, J. H., Krauss, R. M., Gildengorin, G. L., Goldrich, A. M., Block, D. S.,

Abbreviations: aka, also known as; BMI, body mass index; $\mathrm{BP}$, blood pressure; bpm, beats per minute; CVD, cardiovascular disease; DBP, diastolic blood pressure; DHA, docosahexaenoic acid; HDL-L, large HDL subfraction; HDLPs, total HDL subfractions; HOMA-IR, homeostatic model of insulin resistance; HPMC, hydroxypropylmethylcellulose; HR, heart rate;

(continued on next page)
Shenvi, S. V., McHugh, T. H., Olson, D. A., Ames, B. N. A multicomponent nutrient bar promotes weight loss and improves dyslipidemia and insulin resistance in the overweight/obese: chronic inflammation blunts these improvements. FASEB J. 29, 3287-3301 (2015). www.fasebj.org

Key Words: cardiovascular $\cdot$ dietary intervention $\cdot$ nutritional supplements $\cdot$ lipid particles $\cdot$ HDL cholesterol

OVERCONSUMPTION OF WESTERN DIETS HIGH in calories, sugar, salt, and unhealthy fats, but low in micronutrients [many essential vitamins and minerals (Vs/Ms) and $\omega-3$ fatty acids], fiber, and plant polyphenolics (1-4), is a major cause of the increasing prevalence of obesity worldwide (5-7). Such diets directly contribute to the metabolic dysregulation that usually accompanies obesity (8-11) and is also present in $\sim 25 \%$ of lean individuals $(12,13)$. Metabolic dysregulation includes chronic inflammation, insulin resistance, dyslipidemia, and oxidative stress $(14,15)$. Several metabolic abnormalities, together with visceral adiposity and high blood pressure (BP), are collectively termed "the metabolic syndrome" $(11,16)$. Various aspects of metabolic dysregulation have been shown to be independent risk factors for cardiovascular disease (CVD) and type 2 diabetes, and putative risk factors for the many other obesityassociated diseases including cancer, autoimmune disorders, asthma, and neurodegenerative conditions (17-22).

Because poor diets are a root cause of these health problems, an obvious approach to the obesity epidemic would be to improve dietary habits. However, changing dietary patterns is difficult for many people to initiate and sustain (23-25).

\footnotetext{
${ }^{1}$ Correspondence: Nutrition and Metabolism Center, Children's Hospital Oakland Research Institute, 5700 Martin Luther King Jr. Way, Oakland, CA 94609, USA. E-mail: jmccann@chori.org (J.C.M.); mshigenaga@chori.org (M.K.S.) doi: 10.1096/fj.15-271833
} 
We have developed, guided by 18 small clinical trials conducted over the last 10 years, a low-calorie, fruit-based bar fortified with micronutrients, fiber, and other dietary components inadequate in a typical Western diet (26). This approach was based on the hypothesis that metabolic dysregulation common in the obese (with consequent increased disease risk) is due in large part to what is missing or inadequate in Western diets, and might be improved by increasing intake of these food components.

In addition to the bar having practical application as a nutritional supplement to attenuate the adverse metabolic impact of obesity and hopefully encouraging transition to healthier eating habits, a major goal was to use the nutrient mixture as a scientific tool to investigate mechanisms by which individual dietary components in a complex dietary mixture interact with each other and with human metabolism. Because the composition of the bar is defined and easily manipulated, deconstruction studies aimed at understanding mechanisms are quite feasible, whereas this type of mechanistic detective work would be virtually impossible to do in human trials with a complete diet.

A great deal of evidence points to the impact of dietary deficiencies on metabolic health. For example, low intake of fruits, vegetables, and fish by the great majority of the population in the United States $(1,27)$, with consequent inadequate intake of many essential V/Ms (28), results in low $\mathrm{V} / \mathrm{M}$ status, which is particularly apparent in obese people (29-33). Triage theory (34-37) provides a mechanistic rationale for why essential $\mathrm{V} / \mathrm{M}$ inadequacies common in Western diets increase future chronic disease risk. Research also links other dietary deficiencies common in typical Western diets to increased risk for chronic disease or metabolic dysregulation. Examples include low intake of dietary fiber (38-40) and its fermentation products [shortchain fatty acids $(41,42)$ and glutamine $(43-45)]$, plant polyphenolics (46-49) and $\omega-3$ fatty acids (50).

Throughout development of the nutrient mixture, formulation modifications to improve palatability and efficacy were guided by small clinical trials that examined effects of formulation modifications on a range of clinical biochemical and anthropometric measures [(51); unpublished results]. A simple and economical experimental design was used for these trials. Participants acted as their own control subjects and were not asked to modify their existing diets during the course of the trial, consistent with our hypothesis that adding back inadequate dietary components would be sufficient to result in positive change. For further discussion on development of the nutrient bar, see our earlier paper (51).

\section{Background/rationale for the current report}

Early clinical trials were of short duration (2 wk) and included healthy, predominantly lean, or only slightly overweight adults. Our previous report (51) indicated that twice-daily consumption of the nutrient bar for $2 \mathrm{wk}$

(continued from previous page)

hsCRP, high-sensitivity C-reactive protein; IDL, intermediatedensity lipoprotein; OW/OB, overweight/obese; PPAR, peroxisome proliferator-activated receptor; RCT, reverse cholesterol transport; SAA, serum amyloid A; TC, total cholesterol; TG, triglyceride; $\mathrm{V} / \mathrm{M}$, vitamins and minerals resulted in a striking increase in most participants in HDLcholesterol (HDL-c), particularly the large HDL subfraction [designated HDL-L or HDL-2b (10.5-14.5 nm)]. HDL-2b is generally considered to be associated with less future CVD risk $(52,53)$ and may reflect increased reverse cholesterol transport (RCT), an antiatherogenic function of HDL (54).

Subsequent trials included both $2 \mathrm{wk}$ and 2 month time points and approximately equal numbers of lean and overweight/obese (OW/OB) adults. This report presents results of 3 of these 2 month trials using bars of comparable fiber and nutrient composition. The major goal of the analysis was to test whether bar consumption without other lifestyle modifications could shift metabolic dysregulation in the OW/OB toward a "leaner" profile, and to confirm, and extend to 2 months, results of earlier 2 wk trials in predominantly lean individuals (51). Plasma concentrations of standard clinical metabolic and anthropometric measures, lipid protein subfractions, the adipokine adiponectin (55), and the acute phase protein serum amyloid A (SAA) (56) were quantified at baseline, and after 2 and $8 \mathrm{wk}$ of twice-daily consumption of the nutrient bar.

\section{MATERIALS AND METHODS}

\section{Composition of the nutrient bars}

The nutrient bars used in this study were similar to the prototype bar described previously (51). The major difference in the bars utilized in this study compared to the prototype bar (51) is the substitution of half of the soluble fiber with hydroxypropylmethylcellulose (HPMC), a highly viscous, nonfermentable soluble fiber (57). Bars used in the 3 trials presented here were identical except in amounts of some vitamins (vitamins $\mathrm{A}, \mathrm{D}_{3}$, and $\mathrm{K}_{1}$ and folate) and some fruits with high polyphenol (anthocyanin) content, though these differences did not affect outcome distributions (see "Statistical analysis"). Each trial used a different bar. Nutrient profiles of the 3 bars are in Table 1.

\section{Study cohort}

A total of 43 generally healthy adults participated in $\geq 1$ of 3 identical 2-month trials conducted over a period of 4 years. There were 10 participants in 2 trials; 5 were in 3 trials. Each trial was separated by $>1$ year. There were 2 participants excluded from the analysis because their baseline fasting blood glucose was $>126 \mathrm{mg} / \mathrm{dl}$, indicating diabetes. One participant was excluded from analysis because high-sensitivity C-reactive protein (hsCRP) values for all 3 time points were $>10 \mathrm{mg} / \mathrm{L}$, indicating probable infection (60). There were 4 individual hsCRP data points $>10$ (in 4 participants) also excluded. All but one of these high values were supported by documentation of either a cold or allergy at the time of the clinical research center visit. Data points corresponding to these 4 excluded values were also removed for all non-hsCRP parameters analyzed. A single outlier baseline value was also removed from the SAA data set that was 5 sDs greater than the mean. The trials were identical in design and involved twicedaily intake of the nutrient bar. Characteristics of the study cohort are shown in Table 2. Exclusion criteria were intercurrent infectious disease, untreated stage II hypertension, and medication for diabetes or dyslipidemia. Clinical trials were approved by the institutional review board of Children's Hospital and Research Center Oakland. All participants signed informed consent forms prior to enrollment. 
TABLE 1. Composition of bars

\begin{tabular}{|c|c|c|c|}
\hline Bar components & Bar 1 & Bar 2 & Bar 3 \\
\hline Total calories (kcal) & 107 & 124 & 107 \\
\hline Total fat $(\mathrm{g})$ & 5.04 & 5.09 & 5.04 \\
\hline Saturated fat $(\mathrm{g})$ & 2.52 & 2.54 & 2.52 \\
\hline Trans fat $(\mathrm{g})$ & 0.0 & 0.0 & 0.0 \\
\hline Cholesterol (mg) & 0.0 & 0.0 & 0.0 \\
\hline DHA, 22:6 n-3 (mg) & 200 & 200 & 200 \\
\hline Sodium (mg) & 2.71 & 3.002 & 2.71 \\
\hline Potassium (mg) & 142 & 158 & 142 \\
\hline Total carbohydrate $(\mathrm{g})$ & 19.7 & 25.4 & 19.7 \\
\hline Fiber, total dietary $(\mathrm{g})$ & 7.31 & 8.79 & 7.31 \\
\hline Sugars (g) & 7.58 & 11.0 & 7.58 \\
\hline Total protein $(\mathrm{g})$ & 3.78 & 3.91 & 3.78 \\
\hline $\begin{array}{l}\text { Vitamin A (retinol activity } \\
\text { equivalents) }\end{array}$ & 71.9 & 35.6 & 71.9 \\
\hline$\beta$-Carotene $(\mu \mathrm{g})$ & 201 & 180 & 201 \\
\hline Calcium (mg) & 287 & 362 & 287 \\
\hline Vitamin D3 (IU) & 0.0 & 2300 & 200 \\
\hline Vitamin K1 $(\mu g)$ & 45 & 36 & 45 \\
\hline Riboflavin (mg) & 0.63 & 0.65 & 0.63 \\
\hline Vitamin B6 (mg) & 0.69 & 0.71 & 0.69 \\
\hline Vitamin B12 $(\mu \mathrm{g})$ & 0.80 & 0.80 & 0.80 \\
\hline Pantothenic acid (mg) & 1.39 & 1.35 & 1.39 \\
\hline Zinc (mg) & 2.8 & 2.84 & 2.8 \\
\hline Copper $(\mu g)$ & 283 & 287 & 283 \\
\hline Chromium $(\mu g)$ & 33 & 33 & 33 \\
\hline Vitamin C (mg) & 105 & 106 & 105 \\
\hline Iron $(\mathrm{mg})$ & 1.89 & 1.98 & 1.89 \\
\hline Vitamin E ( $\alpha, \gamma$ tocopherols) $(\mathrm{mg})$ & 6.63 & 6.70 & 6.63 \\
\hline Thiamine (vitamin B1) (mg) & 0.43 & 0.44 & 0.43 \\
\hline Niacin $(\mathrm{mg})$ & 7.77 & 7.90 & 7.77 \\
\hline Folate $(\mu g)$ & 316 & 558 & 316 \\
\hline Biotin $(\mu \mathrm{g})$ & 7.5 & 7.5 & 7.5 \\
\hline Phosphorus (mg) & 42.2 & 45.1 & 42.2 \\
\hline Magnesium (mg) & 179 & 180 & 179 \\
\hline Selenium $(\mu g)$ & 6.24 & 6.20 & 6.24 \\
\hline Manganese (mg) & 0.36 & 0.36 & 0.36 \\
\hline Choline (mg) & 127 & 128 & 127 \\
\hline Glutamine (g) & 1.0 & 1.0 & 1.0 \\
\hline Lactate $(\mathrm{mg})$ & 0.0 & 326 & 0.0 \\
\hline Glycerine $(\mathrm{g})$ & 1.00 & 1.50 & 1.00 \\
\hline Total polyphenols (mg) & 473 & 515 & 473 \\
\hline Monomeric polyphenols (mg) & 87.8 & 157 & 87.8 \\
\hline
\end{tabular}

Values are amounts contained in 1 bar; dosage is 2 bars per day. Values were calculated from U.S. Department of Agriculture (USDA) tables (58) and individually added nutrients. Fruit concentrate polyphenol concentrations are derived from the USDA Database for the Flavonoid Content of Selected Foods, Release 2.1 (59). The Nutrient Database numbers are 09050, 09078, 97074, and 09279. Polyphenol content of blueberry powder was provided by the Highbush Blueberry Council. The patent is pending (26).

\section{Intervention}

The study design was an open label, nonrandomized 8 wk clinical trial in which participants acted as their own control subjects. Participants were advised to discontinue all vitamin, mineral, and fiber supplements and any other nutraceuticals $2 \mathrm{wk}$ before the initiation of each trial. Compliance with these guidelines as well as absence of intercurrent infectious disease was assessed by selfreport. Consumption of 2 bars each day was advised, with the first to be eaten before noon and the second in either the afternoon or evening. Participants were advised to drink a minimum of 8 ounces of water with each bar. No guidelines as to whether to use the bar as a meal replacement or a supplement were given. Baseline, 2 and $8 \mathrm{wk}$ visits to the clinical research center included measurements of height, weight, and waist circumference taken at the umbilicus. Compliance with bar consumption averaged $95 \%$, as assessed by questionnaire at each visit to the clinical research center. Each physical measurement was taken twice and averaged. BP and heart rate (HR; Dinamap, GE Healthcare, Wauwatosa, WI, USA) were assessed in triplicate and averaged. Fasting venous blood samples were taken in EDTAcontaining tubes and immediately processed.

\section{Biochemical analyses}

Lipid profiles

Plasma samples prepared within 15 min of collection were kept at $4^{\circ} \mathrm{C}$ throughout processing. For 1 of the 3 trials analyzed, the basic lipid panel [total cholesterol (TC), triglycerides (TGs), HDL-c, and LDL cholesterol (LDL-c) ] was determined as follows. Plasma TC and TG concentrations were determined by enzymatic 
TABLE 2. Baseline metabolic and anthropometric characteristics of $O W / O B$ and lean participants

\begin{tabular}{|c|c|c|}
\hline Characteristics & $\mathrm{BMI}<25$ & $\mathrm{BMI} \geq 25$ \\
\hline Mean clinical measures (SD) & $(n=29)$ & $(n=30)$ \\
\hline Age (years)* & $43.4(14.3)$ & $52.7(12.6)$ \\
\hline Female sex $(\%)^{a}$ & 86.7 & 40 \\
\hline \multicolumn{3}{|l|}{ Physical } \\
\hline BMI* & $22.6(1.7)$ & $29.7(3.4)$ \\
\hline Weight $(\mathrm{kg})^{*}$ & $62.3(8.4)$ & $92.0(16.8)$ \\
\hline Waist circumference $(\mathrm{cm}) *$ & $80.5(6.5)$ & $104.0(11.5)$ \\
\hline Systolic BP $(\mathrm{mmHg}) *$ & $112.2(11.0)$ & $120.8(9.7)$ \\
\hline Diastolic BP (mmHg)* & $70.7(7.5)$ & $77.8(8.3)$ \\
\hline HR (bpm) & $64.7(11.9)$ & $67.0(6.9)$ \\
\hline \multicolumn{3}{|l|}{ Lipids } \\
\hline HDL-c $(\mathrm{mg} / \mathrm{dl})^{*}$ & $68.7(20.8)$ & $49.8(12.5)$ \\
\hline LDL-c $(\mathrm{mg} / \mathrm{dl})^{\dagger}$ & $101.3(34.0)$ & $124.4(36.6)$ \\
\hline $\mathrm{TC}(\mathrm{mg} / \mathrm{dl})$ & $186.1(35.6)$ & $201.9(36.6)$ \\
\hline Non-HDL-c $(\mathrm{mg} / \mathrm{dl}) *$ & $115.0(37.9)$ & $149.2(36.6)$ \\
\hline TGs $(\mathrm{mg} / \mathrm{dl}) *$ & $80.7(41.2)$ & $157.4(118.9)$ \\
\hline VLDL-c $(\mathrm{mg} / \mathrm{dl}) *$ & $16.1(8.2)$ & $31.5(23.8)$ \\
\hline TG/HDL-c* & $1.4(1.2)$ & $3.9(4.7)$ \\
\hline \multicolumn{3}{|l|}{ Insulin resistance } \\
\hline Glucose $(\mathrm{mg} / \mathrm{dl})^{*}$ & $93.3(7.7)$ & $102.8(7.5)$ \\
\hline Insulin $(\mathrm{mU} / \mathrm{L})^{*}$ & $6.4(3.9)$ & $13.3(6.9)$ \\
\hline HOMA-IR* & $1.4(0.8)$ & $3.4(1.7)$ \\
\hline \multicolumn{3}{|l|}{ Inflammation related } \\
\hline $\operatorname{hsCRP}(\mathrm{mg} / \mathrm{L}) *$ & $0.87(1.3)$ & $2.1(1.6)$ \\
\hline Adiponectin $(\mathrm{ng} / \mathrm{ml}) *$ & $6797(5895)$ & $3179(2858)$ \\
\hline $\mathrm{SAA}(\mathrm{ng} / \mathrm{ml})$ & $918.4(667.7)$ & $3887(8526)$ \\
\hline Mean lipoprotein particle measurements (SD) & $(n=28)$ & $(n=30)$ \\
\hline \multicolumn{3}{|l|}{ HDL particles } \\
\hline HDL-2b $(\mathrm{nM}) *$ & $3187(1959)$ & $1467(967.1)$ \\
\hline HDL3_2a (nM) & $5548(1788)$ & $5686(1391)$ \\
\hline Total $(\mathrm{nM})^{\dagger}$ & $8736(2704)$ & $7152(1747)$ \\
\hline \multicolumn{3}{|l|}{ LDL particles } \\
\hline Peak diameter $(\AA) *$ & $224.7(6.1)$ & $219.8(6.2)$ \\
\hline LDL I (nM) & $346.3(128.3)$ & $346.0(145.6)$ \\
\hline $\operatorname{LDL} \mathrm{IIa}(\mathrm{nM})^{\dagger}$ & $210.0(98.1)$ & $267.2(92.4)$ \\
\hline LDL IIb $(\mathrm{nM}) *$ & $205.2(103.1)$ & $297.2(110.9)$ \\
\hline LDL IIIa $(\mathrm{nM})^{\dagger}$ & $147.7(121.3)$ & $248.2(172.0)$ \\
\hline LDL IIIb (nM) & $52.5(48.0)$ & $88.4(82.7)$ \\
\hline LDL IVa (nM) & $57.3(30.9)$ & $76.0(48.1)$ \\
\hline LDL IVb (nM) & $52.6(23.3)$ & $65.9(26.9)$ \\
\hline LDL IVc (nM) & $32.8(10.2)$ & $37.0(15.1)$ \\
\hline Total $(\mathrm{nM}) *$ & $1105(354.4)$ & $1426(313.8)$ \\
\hline \multicolumn{3}{|l|}{ VLDL and IDL particles } \\
\hline IDL I $(n M)$ & $170.8(65.3)$ & $188.3(58.5)$ \\
\hline IDL II $(\mathrm{nM})^{\dagger}$ & $277.7(131.7)$ & $204.8(76.4)$ \\
\hline VLDL small (nM) & $72.7(31.9)$ & $72.7(24.6)$ \\
\hline VLDL intermediate $(\mathrm{nM}) *$ & $49.6(26.6)$ & $65.8(24.1)$ \\
\hline VLDL large $(\mathrm{nM}) *$ & $15.0(12.3)$ & $25.7(14.5)$ \\
\hline
\end{tabular}

$n$ refers to the number of observations measured, not the number of participants (see Materials and Methods). The number of observations averaged for each measure is indicated at the head of each column unless otherwise indicated. BMI $<25: n=23$ (non-HDL), $n=27$ (adiponectin), and $n=5$ (SAA). BMI $\geq 25: n=28$ (LDL-c), $n=22$ (non-HDL), $n=30$ (adiponectin), and $n=18$ (SAA). The differences in this table are not intended to represent a definitive comparison because the lean and OW/OB groups were not matched for age, sex, or ethnicity, which are known to affect the metabolic profile. Ethnicities were BMI $<25$ (48\% Caucasian, 31\% Asian-American, 7\% Hispanic, 7\% unknown, 3\% African American, and $3 \%$ other) and BMI $\geq 25$ (58\% Caucasian, $10 \%$ Asian-American, $16 \%$ Hispanic, $10 \%$ unknown, and 6\% African American). HDL3_2a, small HDL (7.6-10.5 nm). For HDL, LDL, and other particle definitions, see Abbreviations. ${ }^{a}$ No significant difference by $\chi^{2}$ analysis. $* P<0.01 ;{ }^{\dagger} P<0.05$.

procedures on an Express 550 Plus analyzer (Ciba Corning, Oberlin, OH, USA) controlled by the U.S. Centers for Disease Control and Prevention-U.S. National Institutes of Health National Heart, Lung, and Blood Institute standardization monitoring program. HDL-c was measured after dextran sulfate precipitation of plasma. LDL-c was calculated using a standard formula (61) for all samples with TG concentrations $<400 \mathrm{mg} / \mathrm{dl}$. For the other 2 trials analyzed, the basic lipid panel (TC, TGs, HDL-c, and LDL-c) was determined by a commercial provider (ARUP Laboratories, Salt Lake City, UT, USA). Ion mobility 
analysis was used to measure concentrations of lipoprotein subfractions in all 3 trials, as previously described (62).

\section{Other measures}

Plasma fasting glucose, insulin, and hsCRP were measured using standard procedures by a commercial provider (ARUP Laboratories). Insulin resistance was estimated using the homeostatic model of insulin resistance (HOMA-IR) calculated as fasting glucose (milligrams per deciliter) $\times$ fasting insulin (milli-international units per liter $) \div 405$. High molecular weight adiponectin was measured by solid-phase sandwich ELISA (Quantikine; R\&D Systems, Minneapolis, MN, USA). SAA was measured using detection antibodies that emit light upon electrochemical stimulation (Meso Scale Discovery, Rockville, MD, USA).

\section{Statistical analysis}

Prior to pooling data from the 3 trials, quantitative measures and changes from baseline to 2 and $8 \mathrm{wk}$ were assessed by ANOVA within each trial. Outcome distributions were similar in all 3 trials, and results were pooled. All statistical analyses were performed using SAS (version 9.3; SAS Institute, Cary, NC, USA). Variables included standard clinical metabolic and anthropometric measures and lipoprotein subfraction concentrations. Means \pm SE were calculated for the various subgroups and time points. Correlations were computed using Spearman's nonparametric estimates. Data were examined for assumptions of normality using measures of skewness and kurtosis, plots, and the Anderson-Darling test. Log transformations were performed for highly skewed data (HOMA-IR, insulin, hsCRP, TGs, SAA, and adiponectin). Initial bivariate analysis using Student's $t$ test was conducted to compare baseline values between lean and OW/OB. Linear regression models were constructed on the continuous outcomes and on changes from baseline. Bar-induced changes were examined over time in the $\mathrm{OW} / \mathrm{OB}$ and in the $2 \mathrm{OW} / \mathrm{OB}$ subgroups using general linear models with time treated as repeated measures. The generalized estimating equation approach, with an exchangeable working correlation structure, was used to account for the within-person correlation in outcomes at different time points (i.e., statistical analysis included adjustment for participants who were in $>1$ trial). A significance level of 0.05 was used for all statistical tests. Because multiple statistical tests were conducted, some false positives may have occurred.

\section{RESULTS}

\section{Baseline characteristics of lean and OW/OB participants}

Baseline metabolic characteristics of lean and $\mathrm{OW} / \mathrm{OB}$ participants are shown in Table 2 and reflect recognized differences between these groups (63-68). As shown, HDL-c is significantly lower in the OW/OB, and BP, LDL-c, TGs, insulin resistance (as measured by HOMA-IR), insulin, glucose, and inflammation (as measured by hsCRP) are all significantly higher. Adiponectin and SAA also reflect known differences between the OW/OB and lean. Adiponectin is significantly higher in the lean $(55,69)$, and $\mathrm{SAA}$ is higher in the OW/OB (70).

Significant lipoprotein subfraction differences between the $\mathrm{OW} / \mathrm{OB}$ and lean groups are 1) higher concentrations of HDL-2b and intermediate-density lipoprotein (IDL) II in the lean, 2) greater LDL peak diameter in the lean, and 3) lower concentrations of LDL IIb and large VLDL (very LDL) in the lean. In addition, as expected (71), across all
$\mathrm{OW} / \mathrm{OB}$ and lean participants, concentrations of small LDL subfractions are strongly and positively correlated with TG concentration and strongly and negatively correlated with HDL-c. The correlation coefficient of the sum of the 2 most atherogenic small subfractions (LDL IIb and IIIa) (72) with HDL-c is $-0.74(P<0.001 ; n=60)$ and with TGs is $+0.71(P<0.001 ; n=60)$.

\section{Effects of 2 and 8 wk twice-daily consumption of 2 nutrient bars in lean and $\mathrm{OW} / \mathrm{OB}$ healthy adults}

\section{Effects of nutrient bar consumption in the lean}

Previously, we reported that consumption of 2 nutrient bars a day for $2 \mathrm{wk}$ by healthy, predominantly lean [body mass index $(\mathrm{BMI})<25$ ] or slightly overweight adults significantly increased HDL-c, particularly the HDL-2b [also known as (aka) HDL-L] (51). Similar results were observed at $2 \mathrm{wk}$ for lean participants in this study and persisted at $8 \mathrm{wk}$, as shown in Fig. 1. HDL-c increased in $76 \%$ of participants, with an overall average increase of $4.1 \pm 1.0 \mathrm{mg} / \mathrm{dl}$ $(P<0.001)$, and HDL-2b increased $492 \pm 148 \mathrm{nM}(P<0.007)$. The additional major change observed in this study was a large increase in the adipokine adiponectin, not measured in our earlier study (51), which also increased very significantly at $2 \mathrm{wk}(+1026 \pm 405 \mathrm{ng} / \mathrm{ml} ; P<0.002)$ and 8 wk $(+1475 \mathrm{ng} / \mathrm{ml} ; P=0.005)$.

Additional parameters for which changes were statistically significant at $8 \mathrm{wk}$ included total HDL subfractions (HDLPs) $(+859 \pm 296 \mathrm{nM} ; P=0.0040)$ and TC $(+9.5 \pm 3.2 \mathrm{mg} / \mathrm{dl} ; P=0.0029)$, not unexpected given the robust increases in HDL measures, and several other statistically significant changes: non-HDL cholesterol $(+6.6 \pm 3.1 \mathrm{mg} / \mathrm{dl} ; P=0.044)$, waist circumference $(+1.1 \pm 0.6 \mathrm{~cm} ; P=0.042)$, and LDL IIa $(+20.4 \pm 9.2 \mathrm{nM}$; $P=0.047)$. There were no statistically significant changes

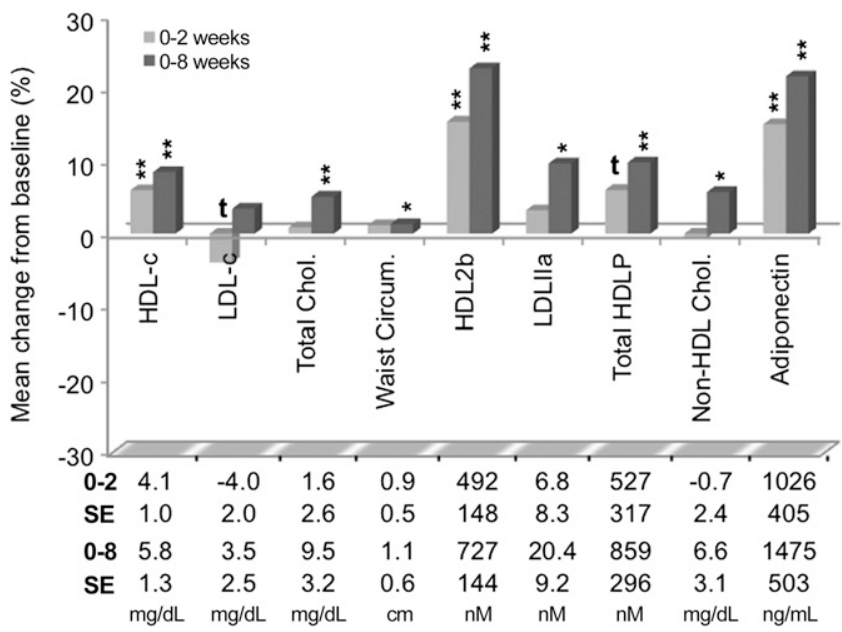

Figure 1. Effects of the nutrient bar in the lean $(\mathrm{BMI}<25)$ after 2 and 8 wk consumption of 2 nutrient bars each day. Chol., cholesterol; Circum., circumference. Values plotted are changes from baseline, averaged across all participants and plotted as percentage of the overall baseline mean for each endpoint. Average changes and SE are specified below the figure. HDL-2b is one of the 2 classes of HDL subfractions identified by the lipid particle-sizing assay and is defined in Abbreviations. $* P<0.05 ; * * P<0.01 ;{ }^{t} P<0.10$. 
in any other biochemical or anthropometric measures at $8 \mathrm{wk}$ in the lean group (data not shown).

\section{Effects in the $O W / O B$}

Bar-induced changes after 2 and 8 wk in the OW/OB are shown for metabolic (Fig. 2A) and anthropometric (Fig. 2B) measures and in Fig. 3 for lipid subfractions. As shown, after 8 wk consumption of 2 bars a day, statistically significant $(P<0.05)$ or trending significant $(P<0.10)$ changes in the direction of baseline values typical of the lean (Table 2) were observed: HDL-c $(+2.4 \pm 1.2 \mathrm{mg} / \mathrm{dl}$; $P=0.078)$; TGs $(-34.3 \pm 21.0 \mathrm{mg} / \mathrm{dl} ; P=0.061)$; insulin resistance (as measured by HOMA-IR, $-0.60 \pm 0.2$; $P=0.011)$; insulin $(-2.3 \pm 0.90 \mathrm{mU} / \mathrm{L} ; P=0.0088)$; glucose $(-2.2 \pm 1.2 \mathrm{mg} / \mathrm{dl} ; P=0.054)$; and adiponectin $(+743 \pm 431 \mathrm{ng} / \mathrm{ml} ; P=0.079)$ (Fig. $2 A)$. Changes in hsCRP $(-0.30 \pm 0.22 \mathrm{mg} / \mathrm{L})$ and SAA $(-204 \pm 236 \mathrm{ng} / \mathrm{ml})$ were also in the direction of improvement. Improvements in anthropometric measures were also observed, as shown in Fig. 2B: diastolic blood pressure (DBP) $(-2.4 \pm 1.3 \mathrm{mmHg}$; $P=0.082)$; HR $[-3.7 \pm 1.0$ beats per minute $(\mathrm{bpm})$; $P<0.001]$; weight $(-0.80 \pm 0.40 \mathrm{~kg} ; P=0.039)$; and waist circumference $(-1.80 \pm 0.90 \mathrm{~cm} ; P=0.043)$.

Changes in lipid subfractions are shown in Fig. 3. Changes in HDL subfractions (HDL-2b and HDL3_2a) indicate that nutrient bar-induced increase in HDL-c in the $\mathrm{OW} / \mathrm{OB}$ is primarily due to an increase in the HDL-2b (aka HDL-L), as reported previously in predominantly lean individuals (51).

Little change in LDL-c is apparent in Fig. 2A. However, examination of Fig. 3 suggests consistent favorable decreases across the more atherogenic (72) small LDL subfractions (LDL IVa, IVb, and IVc and LDL IIIa and IIIb) and consistent favorable increases in the less atherogenic (72) larger subfractions (LDL I and IIa and IDL 2). Only increases in 2 large subfractions [LDL I $(+40.8 \pm 18.1 \mathrm{nM})$ and IDL $2(+20.7 \pm 10.5 \mathrm{nM})]$ reached statistical significance, and decreases in only 2 small subfractions trended significant [LDL IIIb $(-21.7 \pm 12.4 \mathrm{nM}$; $P=0.069)$ and IIIa $(-44.0 \pm 24.7 \mathrm{nM} ; P=0.077)]$. However, the consistency of downward movement in the small dense subfractions and upward movement in the larger subfractions is persuasive.

In summary, consumption of 2 bars each day for 2 months resulted in positive changes in indicators of cardiovascular health (HDL and LDL dyslipidemia, DBP, and $\mathrm{HR}$ ), insulin resistance (HOMA-IR, insulin, and glucose), and obesity itself (weight and waist circumference). The significant increase in adiponectin is also consistent with improved metabolic health $(55,69,73)$. There were no gastrointestinal or other adverse effects from bar consumption.

\section{Inflammation blunts responsiveness to bar consumption}

In the $O W / O B$, baseline inflammation (hsCRP) is inversely correlated with early (2-wk) increase in all 4 HDL measures and with later (8-wk) increase in less atherogenic LDL and IDL lipid subfractions

As shown, baseline hsCRP in the OW/OB is inversely correlated with bar-induced change from 0-2 wk (but not $0-8 \mathrm{wk})$ in all measures of HDL: HDL-c $(r=-0.42$; $P=0.025)$; HDL3_2a $(r=-0.47 ; P=0.010)$; HDL-2b $(r=-0.44 ; P=0.018)$; and HDLP $(r=-0.55 ; P=0.0021)$ (Fig. 4A-D). Baseline hsCRP was also inversely correlated with bar-induced $0-8 \mathrm{wk}$ (but not $0-2 \mathrm{wk}$ ) change in the less atherogenic LDL subfractions LDL I $(r=-0.52 ; P=0.0044)$ and IDL $2(r=-0.46 ; P=0.015)$. No additional correlations were observed.

In the $O W / O B$, improvement in almost all measures occurs more robustly in those who are less inflamed at baseline

Baseline hsCRP values in $\mathrm{OW} / \mathrm{OB}$ participants are illustrated in Fig. 5. As shown, approximately half of the
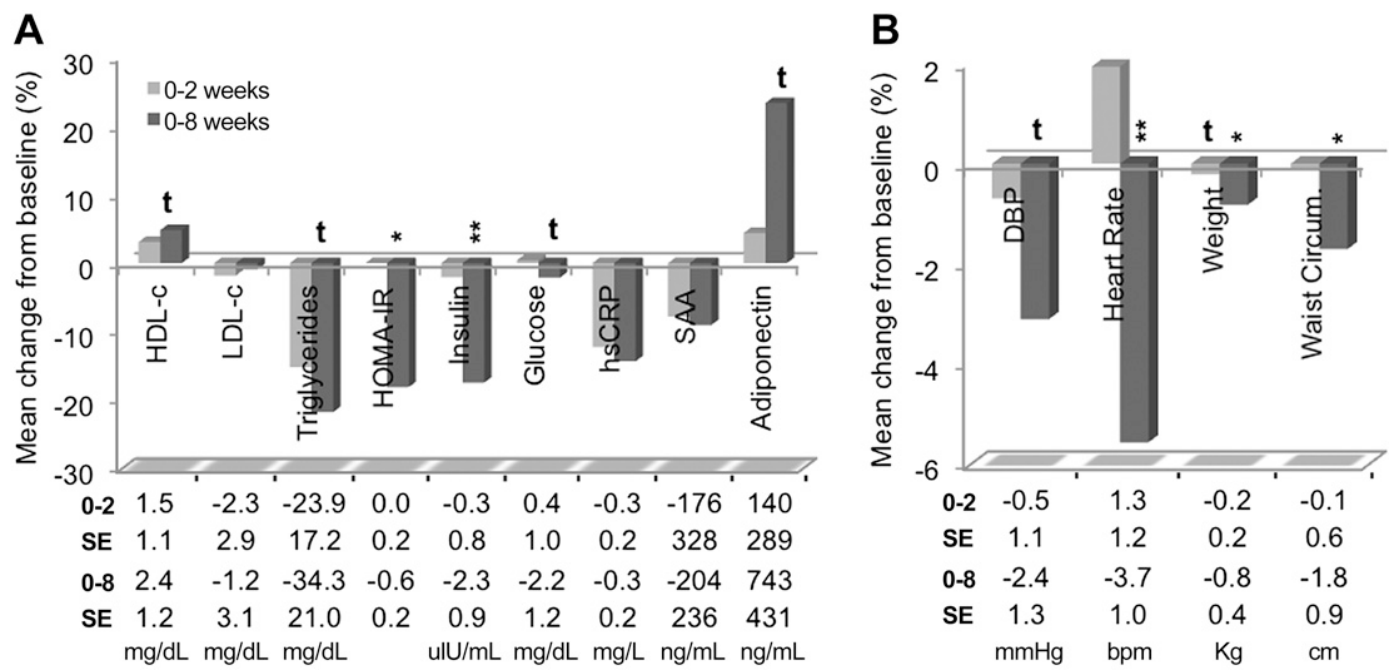

Figure 2. Improvements of measures linked to cardiovascular risk, insulin resistance, inflammation, and obesity in the OW/OB. A) Metabolic. B) Anthropometric. Results after consumption of 2 nutrient bars per day for 2 and 8 wk are shown. $* P<0.05$, $* * P<0.01,{ }^{t} P<0.10$. See Fig. 1 legend for additional information. 


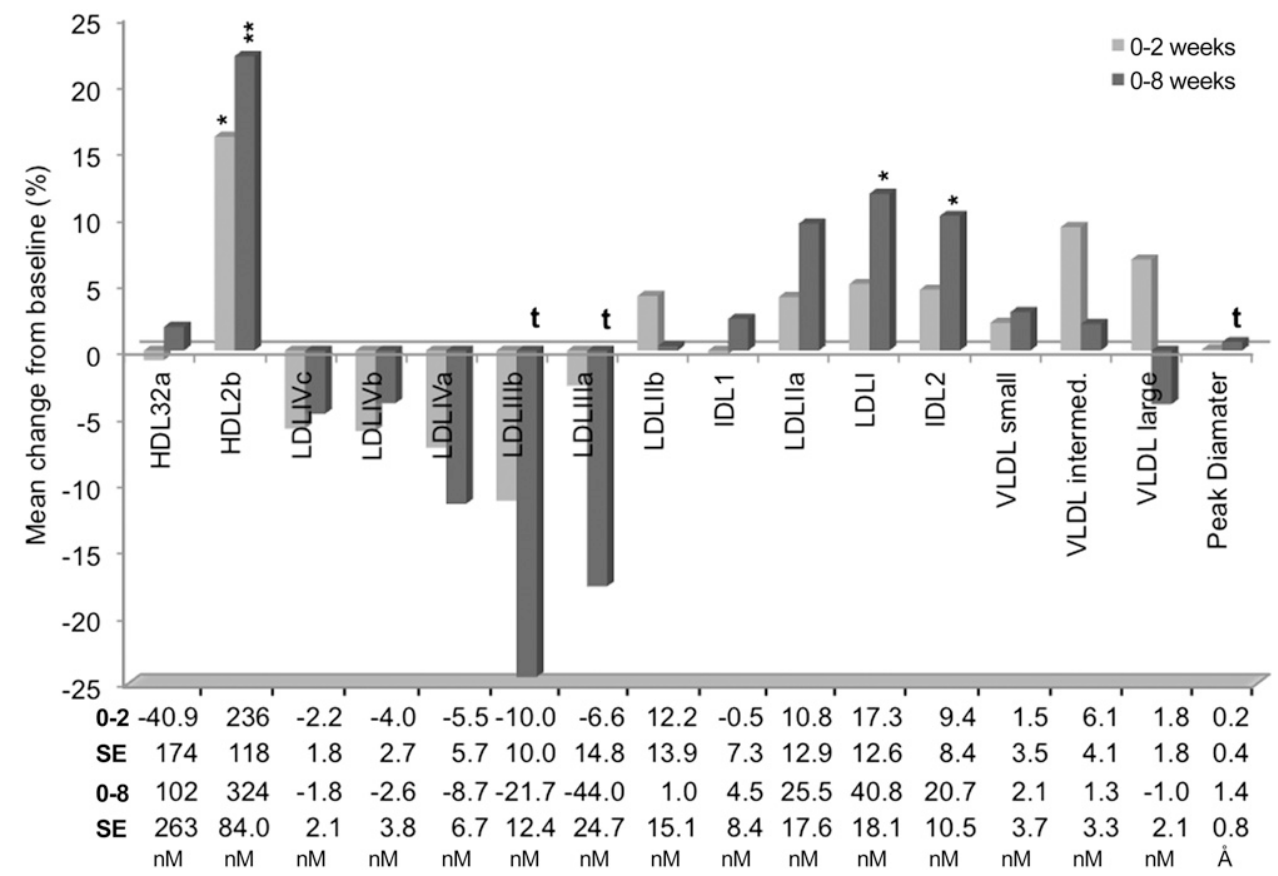

Figure 3. Improvements of lipoprotein subfractions in the OW/OB. HDL, LDL, IDL, and VLDL subfractions are as defined in Abbreviations. intermed., intermediate. $* P<0.05, * * P<0.01$, ${ }^{t} P<0.10$. See Fig. 1 legend for additional information.

baseline hsCRP values fall below an informal cutoff of 1.5, which has been used to classify chronic inflammation linked to CVD risk (74).

In Figs. 6, 7, and 8, effects of nutrient bar consumption for 2 and 8 wk are shown for each of these 2 inflammation subgroups for basic clinical measures (Figs. 6 and 7) and lipoprotein subfractions (Fig. 8). All measures with changes that were either statistically significant or trended significant in either the lower- or higher-inflammation subgroup are plotted. As shown in Figs. $6 A$ and $7 A$, with the exception of adiponectin, nutrient bar-induced change in the less inflamed subgroup is clearly more robust compared to the more highly inflamed subgroup. As shown in Figs. $6 B$ and $7 B$, change in the anthropometric measures is also more robust in the less inflamed subgroup, with the exception of decreased HR. In Fig. 8, a similar pattern is seen for the lipid subfractions. HDL-2b increases in both subgroups, but the response is slower in the more inflamed subgroup. The suggestive realignment of less and more atherogenic LDL and IDL subfractions toward a healthier

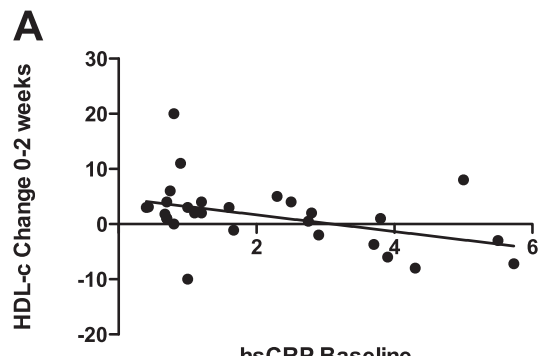

hsCRP Baseline

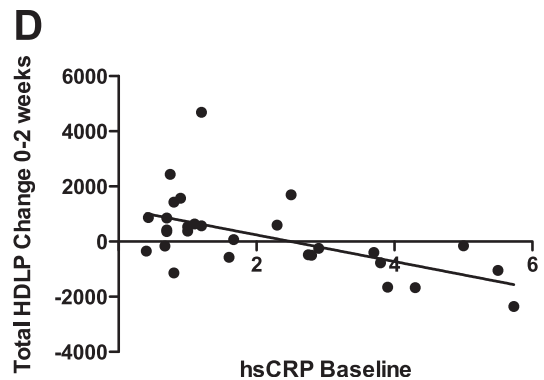

B

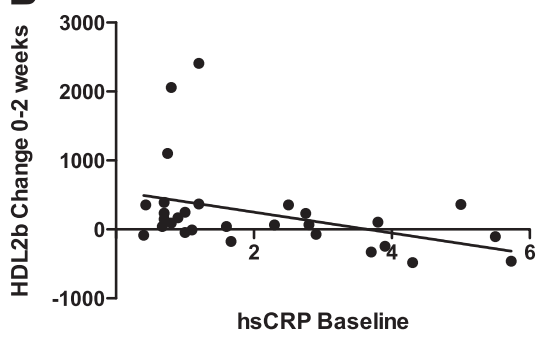

E

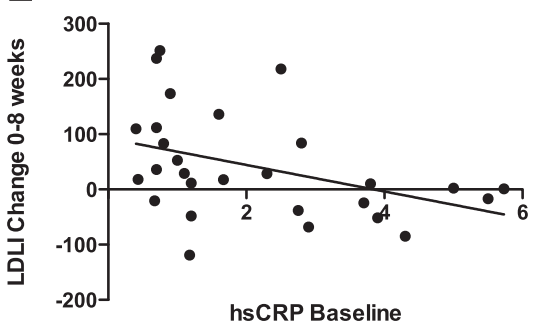

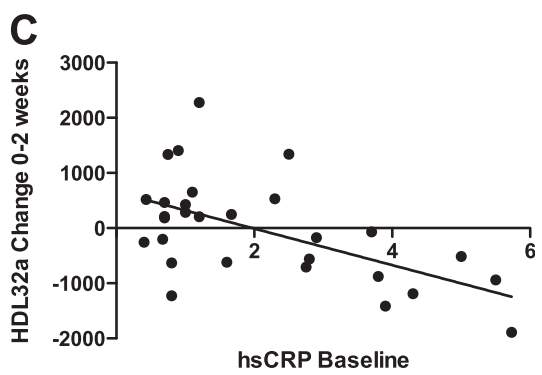

$\mathbf{F}$

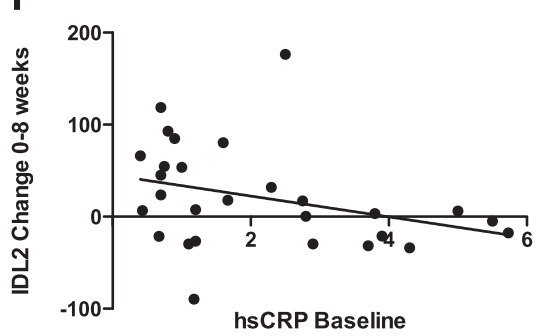

Figure 4. Spearman correlations in the OW/OB between baseline hsCRP and change after consumption of 2 nutrient bars each day for $2 \mathrm{wk}[(A)$ HDL-c (milligrams per deciliter), $(B)$ HDL-2b (nanomolar), $(C)$ HDL3_2a (nanomolar), and $(D)$ HDLP (nanomolar)] or change after 8 wk $[(E)$ LDL I (nanomolar), and $(F)$ IDL 2 (nanomolar)]. Correlation coefficients and $P$ values were $r=-0.42$ and $P=0.025$ (HDL-c), $r=-0.44$ and $P=-0.018$ (HDL-2b), $r=-0.47$ and $P=0.010$ (HDL3_2a), $r=-0.55$ and $P=0.0021$ (HDLP), $r=-0.52$ and $P=0.0044$ (LDL I), and $r=-0.46$ and $P=0.015$ (IDL 2). 
Figure 5. Distribution of baseline hsCRP values among $\mathrm{OW} / \mathrm{OB}$ participants. Each of the 30 observations in the $\mathrm{OW} / \mathrm{OB}$ is plotted as baseline hsCRP (milligrams per liter). All participants with baseline hsCRP values $<1.5 \mathrm{mg} / \mathrm{L}$ were classified as less inflamed, and those with baseline values $>1.5 \mathrm{mg} / \mathrm{L}$ were classified as more inflamed.

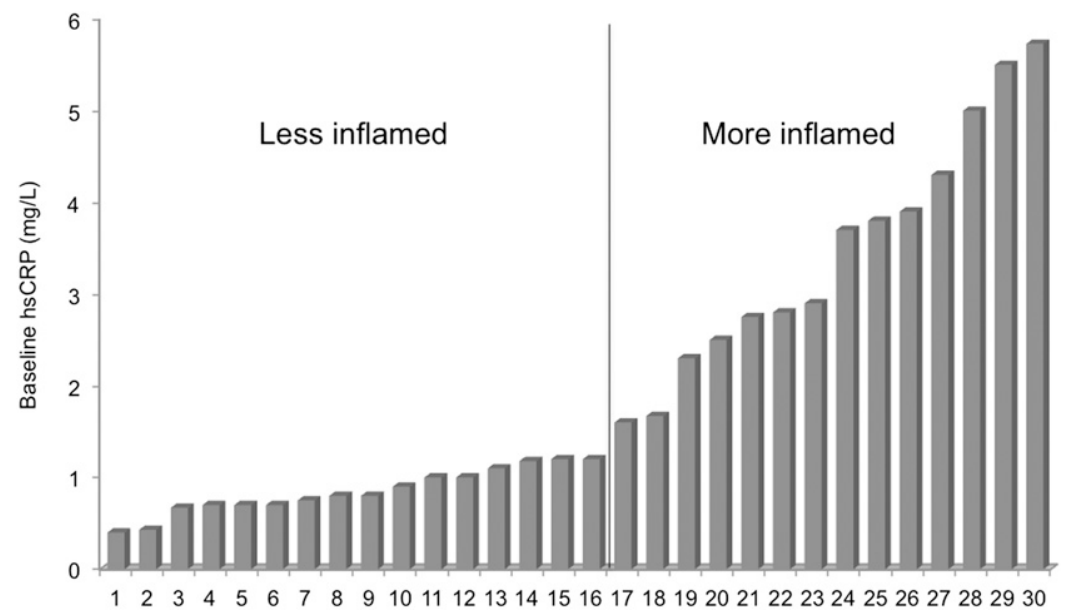

profile after 8 wk of nutrient bar consumption, as observed in the OW/OB group as a whole (Fig. 3), is now clearly shown to be due to bar-induced changes in the lessinflamed subgroup.

Most of the nonsignificant decrease in hsCRP in the OW/OB group (Fig. 2A) occurred in the higherinflamed subgroup; decrease at 8 wk was statistically significant $(-0.78 \pm 0.37 \mathrm{mg} / \mathrm{L} ; P=0.03)$. Changes in SAA were not significant.

\section{DISCUSSION}

A nutrient-dense, high-fiber, fruit-based, low-calorie bar intended to restore nutrient adequacy by filling gaps in Western diets was used as a dietary intervention in three 2-month clinical trials in lean and OW/OB healthy adults to examine effects of consuming 2 bars a day on metabolic and anthropometric measures. Metabolic improvements were seen in both lean and OW/OB participants. Striking improvements occurred in the OW/OB (Figs. 2 and 3), primarily in participants with relatively low levels of chronic inflammation (Figs. 4, 5, 6, 7, and 8). These improvements were in major areas that characterize metabolic dysregulation associated with obesity: HDL and LDL dyslipidemia, as well as other indicators of cardiovascular health (HR and DBP) and insulin resistance (HOMA-IR).

Statistically significant improvements in weight and waist circumference also occurred primarily in the $\mathrm{OW} / \mathrm{OB}$ group with lower levels of chronic inflammation (Figs. $2 B$ and $6 B)$. These reductions were small, not unexpected given the relatively short duration of the intervention and the fact that $\sim 220$ daily kilocalories were added in the form of the nutrition bar without requirements to adjust baseline diet or otherwise change behavior.

This is the first report of which we are aware that documents the resistance of $\mathrm{OW} / \mathrm{OB}$ individuals with higher levels of chronic inflammation to dietary-induced improvements in a wide range of metabolic and anthropometric indicators of obesity-associated dysregulation. The adverse effect of chronic inflammation on diet-induced improvements in some lipids was previously observed (75-79), and one study reported that baseline plasma IL-6 concentrations were significantly higher in individuals more resistant to weight loss (80).

It is of interest that bar-induced improvements at $8 \mathrm{wk}$ in HDL-2b and the adipokine adiponectin appeared to be relatively independent of inflammation, occurring in the
Figure 6. Changes in the lowerinflammation OW/OB subgroup after 2 and 8 wk consumption of the nutrient bar. A) Metabolic. B) Anthropometric. Parameters plotted were selected from those with changes that were statistically significant or trending significant in either of the 2 inflammation subgroups over the 8-wk period. Additional significant or trending significant changes not plotted are as follows. BMI: $0-8=-0.25, P=0.086$; TC: $0-8=-4.93 \mathrm{mg} / \mathrm{dl}, P=0.079$; TG/HDL-c: $0-8=-1.35, P=0.046$; and non-HDL cholesterol: $0-8=-7.10 \mathrm{mg} / \mathrm{dl}, P=0.062$. $* P<0.05,{ }^{*} * P<0.01,{ }^{t} P<0.10$.
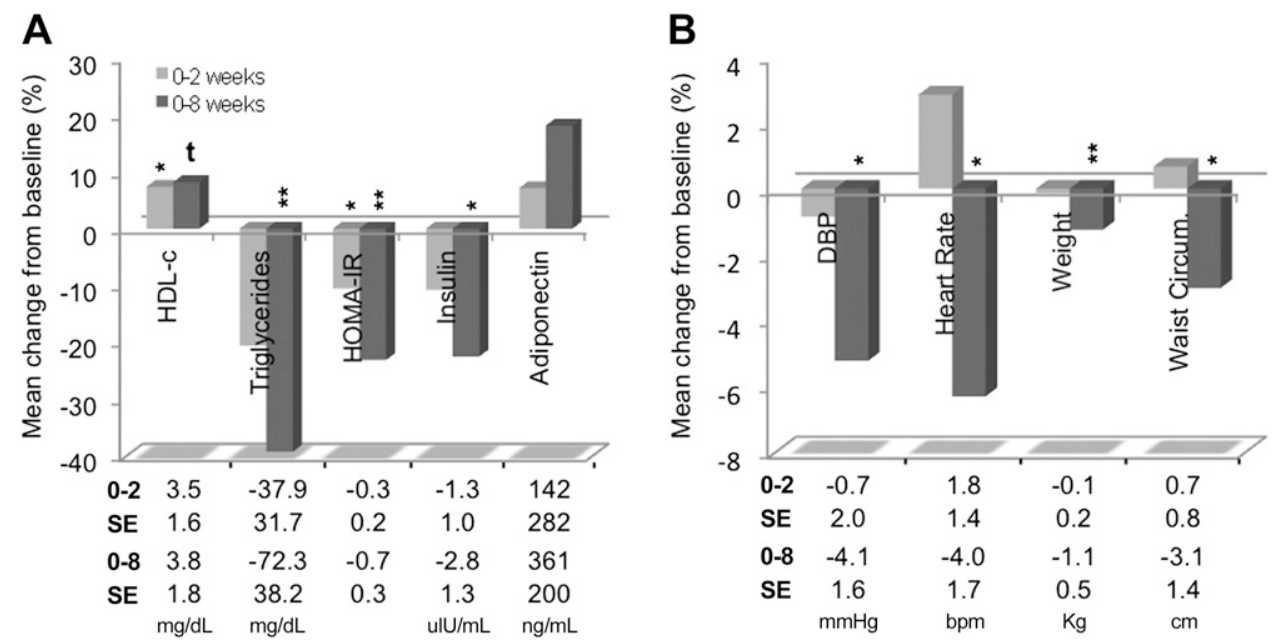

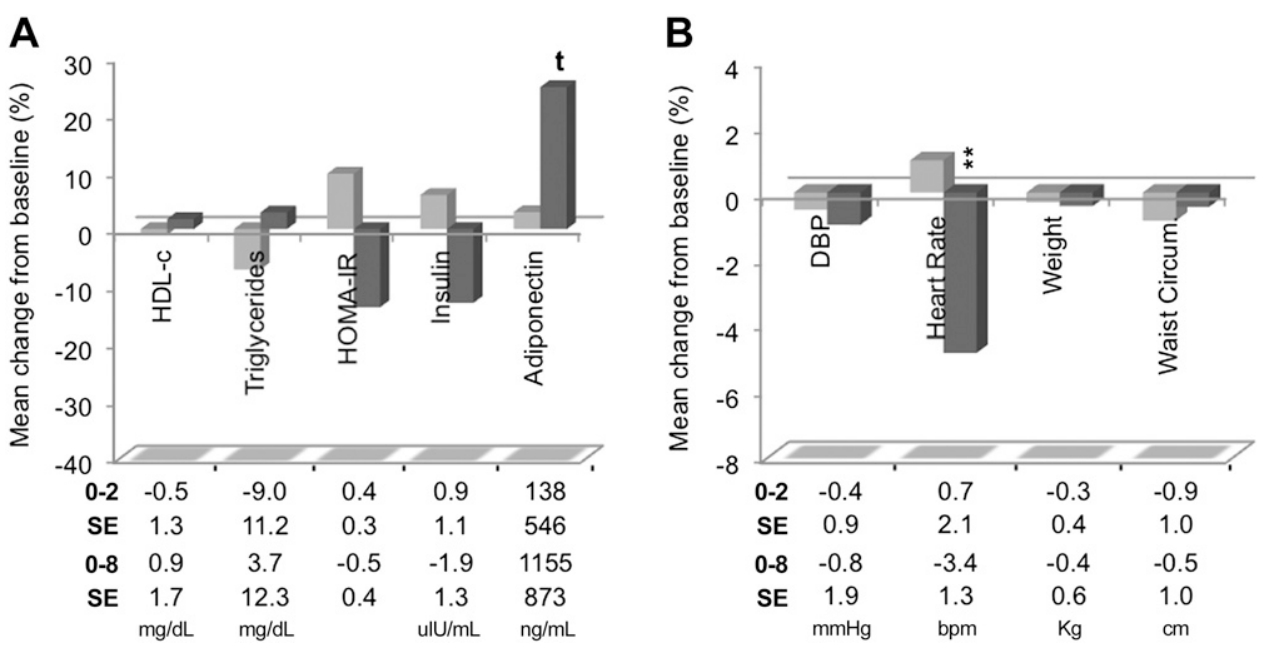

Figure 7. Changes in the higher-inflammation $\mathrm{OW} / \mathrm{OB}$ subgroup after 2 and 8 wk consumption of the nutrient bar. $(A)$ Metabolic and $(B)$ anthropometric measures. Parameters plotted were selected from those with changes that were statistically significant or trending significant in either of the 2 inflammation subgroups over the 8-wk period. The only additional change not plotted was non-HDL cholesterol: $0-8=+6.8 \mathrm{mg} / \mathrm{dl} ; P=0.075$. ** $P<0.01,{ }^{t} P<0.10$.

lean (Fig. 1), in the OW/OB as a whole (Figs. $2 A$ and 3 ), and in both OW/OB inflammation subgroups (Figs. 6A, $7 A$, and 8 ). Higher plasma concentrations of adiponectin have been suggested as an overall biomarker of metabolic health (73) and have been linked to increased HDL-c and decreased inflammation $(55,81)$. Adiponectin was reported to induce RCT $(82,83)$, which could help to explain the bar-induced increase in HDL-2b (54) observed here and previously (51).

\section{Effects of the nutrient bar on inflammation}

Inflammatory response is a recognized mechanism in the pathogenesis of atherosclerosis and related risk for CVD (18). Among several measures of inflammation (including SAA), hsCRP is preferentially recommended for clinical use in identifying individuals at risk (18). In the OW/OB, both hsCRP and SAA appeared to decrease after bar consumption, but results did not reach statistical significance (Fig. 2A). However, there was a statistically significant reduction in hsCRP $(\sim 20 \% ; P=0.030)$ among participants who fell into CVD risk categories considered to be high average or high (Fig. 5) (18). Although a causal role of the nutrient bar in improving inflammation cannot be inferred from these results, it is suggested that the initial effect of the bar in the more inflamed OW/OB subgroup may be to decrease inflammation, which would then allow positive changes in metabolic dysregulation to manifest over a longer period than the 8-wk duration of this intervention. In this regard, it is noted that HDL-2b increased after 2 wks of bar consumption in the lower-inflammation groups (lean, Fig. 1; lower-inflammation OW/OB subgroup, Fig. 8A), but not until 8 wk in the higher-inflammation OW/OB subgroup (Fig. 8B).

\section{Possible mechanisms}

It is suggested that improvements in such a wide range of metabolic and anthropometric measures in the $\mathrm{OW} / \mathrm{OB}$ (Figs. 2, 3, 6, and 8) may be the result of the restoration of impaired underlying metabolic processes due to the resupply by the nutrient bar of critical dietary components
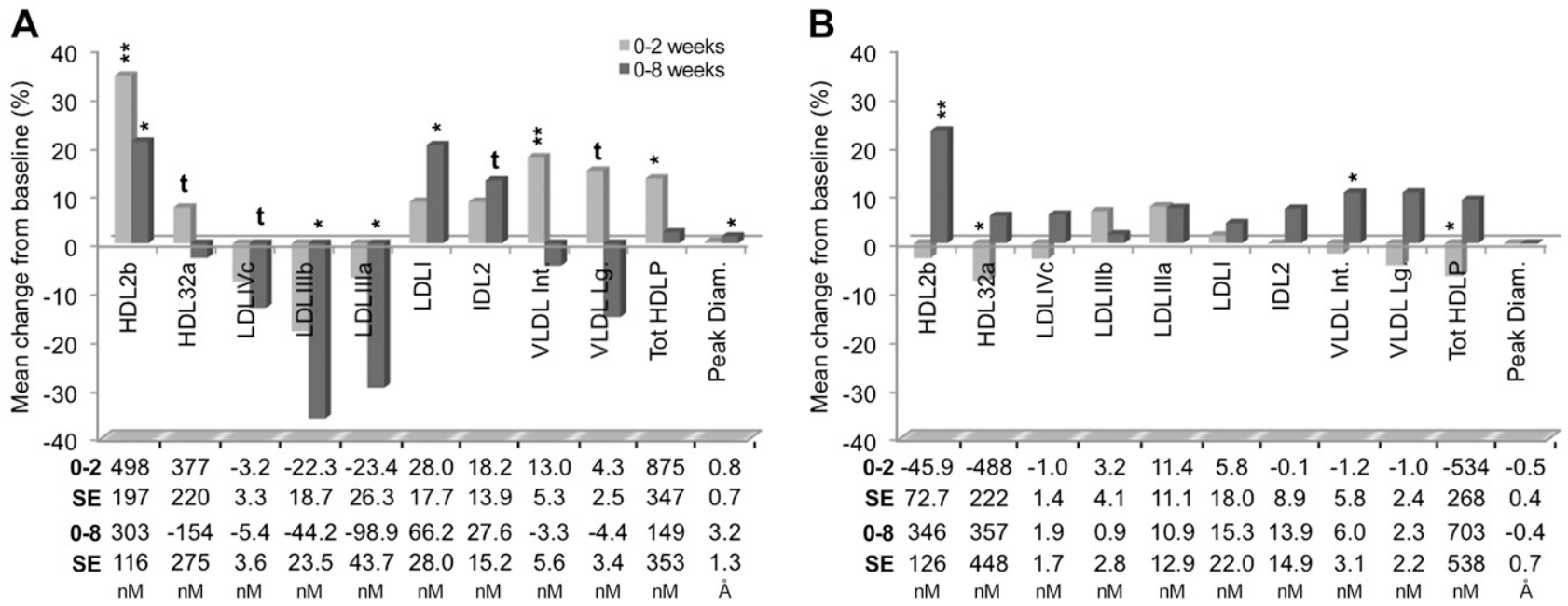

Figure 8. Changes in the lower- and higher-inflammation OW/OB subgroups after 2- and 8-wk consumption of the nutrient bar. A) Lower-inflammation subgroup. B) Higher-inflammation subgroup. Lipid particle subfractions are shown. Parameters plotted were those with statistically significant or trending significant changes in either of the 2 subgroups over the 8-wk period. Int., intermediate; Lg., large; Diam., diameter. $* P<0.05, * * P<0.01,{ }^{t} P<0.10$. 
deficient in Western diets. Mitochondrial stress and impaired gut wall integrity are candidate underlying processes that may be improved by bar consumption. Both of these conditions are common in the obese $(84,85)$, and both are linked to poor diets $(86,87)$ and to insulin resistance and inflammation $(88,89)$. Bar-induced reduction of mitochondrial stress and improved gut integrity would be expected to have multiple beneficial consequences similar to the metabolic improvements observed in this study. The restoration of an internal metabolic environment that manifests a leaner metabolic profile would also allow the metabolic flexibility required for weight loss and clearance of ectopic adiposity $(90,91)$.

\section{Mitochondrial stress}

The metabolic efficiency of mitochondria in converting fuel (carbohydrates, lipids, and amino acids) to ATP decreases in the obese relative to the lean (92). The generation of oxidants is a consequence of the accumulation of NADH over $\mathrm{NAD}^{+}$, which occurs due to chronic hyperglycemia resulting from overnutrition (93-95). Oxidants directly interfere with insulin-signaling efficiency (96-98), and oxidant-initiated oxidative damage triggers inflammation because cells that sustained such injury are cleared by immune cells (98). Fatty acid accumulation resulting from decreased mitochondrial efficiency also inhibits insulin-signaling efficiency $(99,100)$.

There are several ingredients in the nutrient bar that may positively impact mitochondrial stress. High-viscosity dietary fiber HPMC has been shown to slow glucose absorption (101) and to preserve respiratory quotients in rats consuming a high-fat diet (102). Furthermore, 2 nutrient bars (the daily dose) also contain $400 \mathrm{mg}$ docosahexaenoic acid (DHA), a known peroxisome proliferator-activated receptor (PPAR)- $\alpha$ agonist. Activation of the PPAR pathway leads to increased fatty acid oxidation and preferentially reduces small proatherogenic LDL subfractions (103). The bar also contains high concentrations of polyphenolic compounds from fruit and dark chocolate. Polyphenolic consumption in healthy overweight individuals has been shown to increase resting energy expenditure, which would relieve mitochondrial reductive stress described above (104). Polyphenols also increase cellular antioxidant defense by activating Nrf2 phase-2 detoxification pathways that antagonize inflammation (105).

\section{Gut wall integrity}

Gut wall integrity and the intestinal microbiome are impaired by high-fat and high-sugar diets commonly consumed by the obese (106-108). Evidence points to the importance of fiber, its metabolites, and other dietary components $(106,109-111)$ in maintaining a healthy gut barrier $(112,113)$ and intestinal microbiome (114) to prevent diet-induced chronic inflammation and insulin resistance $(84,106,115)$. The consequence of poor nutrition is a condition termed "leaky gut," in which fragments of gram-negative bacteria (LPS aka endotoxin) pass through the gut into systemic circulation, leading to chronic inflammation $(106,116,117)$. The nutrient bar may help to strengthen the gut barrier epithelium through provision of nutrients that support the gut's bioenergetic capacity and thus its resiliency to intestinal permeability (118). These nutrients include soluble fiber and its fermentation products $(26,51)$ such as short-chain fatty acids $(41,42)$, glutamine (43-45), and zinc (119-121). Such barinduced strengthening of the gut epithelium, and consequent reduction in plasma endotoxin, should be possible within the first 2 wk of bar consumption (122), compatible with the observed early ( $2 \mathrm{wk}$ ) rise in HDL-2b and adiponectin. Decreasing endotoxin entry by strengthening the gut wall would result in a reduction in inflammation $(106,123)$ and the consequent endocrine (i.e., insulin and leptin) $(124,125)$ and mitochondrial stress responses to inflammation that make it difficult to lose excess fat and maintain a healthy body weight.

\section{Summary}

It is suggested that the less inflamed OW/OB subgroup is less metabolically impaired and thus better poised to move toward a leaner metabolic profile in response to improved function resulting from nutrients supplied by the bar. The higher-inflammation subgroup must first reduce inflammation. It is posited that reductions in hsCRP (Fig. 2), most of which occurred in the higher-inflammation subgroup, may reflect what is potentially the first step toward a leaner metabolic profile, which may require a longer period to develop in more chronically inflamed individuals than the 8-wk period of the trials analyzed in this report.

\section{Practical implications for weight management programs}

Conventional weight management strategies can be successful [e.g., (126-128)], but results are often disappointing $(24,25)$. Poor weight loss and maintenance of weight loss are, in part, due to the incompletely understood observation that some people lose weight more easily than others, independent of compliance $(23,25,129,130)$. Results presented here suggest that $\mathrm{OW} / \mathrm{OB}$ individuals who respond poorly to a weight loss program may be those that have higher baseline chronic inflammation. Such individuals may require a longer, or different, approach than those that are less inflamed.

Poor compliance is also a major cause of low success rates in weight loss management programs $(24,131,132)$. This is not surprising because these programs typically require dietary and activity modifications that are difficult for many to initiate and sustain. It is suggested that weight management programs will be more successful if interventions, such as that employed here, are used as a first step to help participants transition to healthier eating and lifestyle habits. In this study, participants were not instructed to make any lifestyle changes other than to eat 2 nutrient bars each day. This study design imposed relatively minor restrictions on participants, and compliance was very high $(95 \%)$. The modest but statistically significant loss in weight $(1.1 \pm 0.5 \mathrm{~kg} ; P=0.0051)$ and waist circumference $(3.1 \pm 1.4 \mathrm{~cm} ; P=0.019)$ that occurred in the less inflamed OW/OB subgroup may have been the result of barinduced improvement in metabolic health that enabled 
the metabolic flexibility required to initiate weight loss. Early success in weight management programs may encourage participants toward higher compliance throughout the program, and early identification of participants whose metabolism is resistant to change should also be beneficial.

\section{Potential for use of natural food-based nutrient mixtures as alternatives or companions to drugs used to treat obesity-associated metabolic dysregulation}

Obesity-associated metabolic dysregulation is often treated with drugs: dyslipidemia with statins and fibrates (133, 134), insulin resistance with thiazolidinediones and metformin $(135,136)$, and chronic inflammation with nonsteroidal anti-inflammatory drugs (137). All of these drugs have demonstrated clinical benefits. However, because most drugs act by pharmacologically blocking or accelerating cellular pathways, pleiotropic, often poorly understood and sometimes negative side effects can result $(134,138,139)$. On the other hand, food-based nutrient mixtures, such as the nutrient bar used here, that contain nutrients at normal dietary concentrations are not expected to have significant negative side effects. The full potential of such food-based nutrient mixtures as alternatives or companions to drugs for treatment of metabolic dysregulation associated with obesity has not been given adequate attention.

\section{Limitations}

The clinical trial design used in this and previous (51) nutrient bar trials did not include a placebo control group; instead, participants acted as their own controls. Difficulties in applying the same placebo standards used for drug trials to nutritional interventions have been widely discussed [e.g., (140)]. In addition, dietary intake during the trial was not monitored. Thus, it is not known whether participants altered their food choices or consumed fewer calories during the trials. If such changes occurred, they could have contributed to the positive effects observed.

\section{CONGLUSIONS}

The broad-spectrum metabolic and anthropometric improvements observed after 2 months of twice-daily consumption of a low-calorie food-based nutrient bar aimed at filling gaps in poor diets suggest that it is not necessary to impose severe changes in diet and lifestyle patterns to begin to effect positive changes in the $\mathrm{OW} / \mathrm{OB}$, and also in the lean. Two-month consumption of the nutrient bar did not make the OW/OB lean or completely correct unhealthy metabolism, but it did begin a process of favorable metabolic change. The fact that almost all statistically significant favorable changes occurred in the subgroup of the $\mathrm{OW} / \mathrm{OB}$ with less chronic inflammation suggests an explanation for why some $\mathrm{OW} / \mathrm{OB}$ have difficulty losing weight. This study highlights the power of foodbased, targeted, dietary interventions as alternatives or adjuncts to the use of drugs to treat obesity and associated metabolic dysregulation.

The authors thank Kirsten Graves for construction of the formulation table, Darryl Chow for technical assistance with the database and the serum amyloid $\mathrm{A}$ and adiponectin analyses, Rachelle Woods for assisting with nutrient bar sensory improvement and bar production, the staff at the Pediatric Clinical Research Center at Children's Hospital Oakland, Teresa Klask for invaluable administrative assistance, and the many volunteers who have assisted in this project over the years. R.M.K. thanks Joe Orr for conducting the lipoprotein subfraction analyses. The authors are grateful to several organizations for their generous donations of bar ingredients: Pharmachem Laboratories (Kearny, NJ, USA) for a vitamin and mineral blend; the U.S. Highbush Blueberry Council (Folsom, CA, USA) for blueberry powder; and Dow Chemical (Midland MI, USA) for hydroxypropylmethylcellulose. The authors are also grateful to Henry H. Wheeler for his generous support of their laboratory. All authors read and approved the final manuscript. This work was supported by the Children's Hospital Oakland Research Institute-Ames Foundation (to J.C.M., M.K.S., A.L., A.M.G., D.S.B., and S.V.S.), S.D. Bechtel, Jr. Foundation (to J.H.S.), and Quest Diagnostics (to R.M.K.).

\section{REFERENCES}

1. Kris-Etherton, P. M., Taylor, D. S., Yu-Poth, S., Huth, P., Moriarty, K., Fishell, V., Hargrove, R. L., Zhao, G., and Etherton, T. D. (2000) Polyunsaturated fatty acids in the food chain in the United States. Am. J. Clin. Nutr. 71 (1, Suppl), 179S-188S

2. Carrera-Bastos, P., Fontes Villalba, M., O'Keefe, J. H., Lindeberg, S., and Cordain, L. (2011) The western diet and lifestyle and diseases of civilization. Res. Rep. Clin. Cardiol. 2, 215-235

3. Ricciardiello, L., Bazzoli, F., and Fogliano, V. (2011) Phytochemicals and colorectal cancer prevention-myth or reality? Nat. Rev. Gastroenterol. Hepatol. 8, 592-596

4. Hill, J. O., and Peters, J. C. (1998) Environmental contributions to the obesity epidemic. Science 280, 1371-1374

5. Ogden, C. L., Carroll, M. D., Kit, B. K., and Flegal, K. M. (2013) Prevalence of obesity among adults: United States, 2011-2012. NCHS data brief, no. 131. National Center for Health Statistics, Hyattsville, MD, USA

6. Popkin, B. M. (2007) The world is fat. Sci. Am. 297, 88-95

7. Wijnhoven, T. M., van Raaij, J. M., Spinelli, A., Rito, A. I., Hovengen, R., Kunesova, M., Starc, G., Rutter, H., Sjöberg, A., Petrauskiene, A., O'Dwyer, U., Petrova, S., Farrugia Sant'angelo, V., Wauters, M., Yngve, A., Rubana, I. M., and Breda, J. (2013) WHO European Childhood Obesity Surveillance Initiative 2008: weight, height and body mass index in 6-9-year-old children. Pediatr. Obes. 8, 79-97

8. Pereira, M. A., Kottke, T. E., Jordan, C., O'Connor, P. J., Pronk, N. P., and Carreón, R. (2009) Preventing and managing cardiometabolic risk: the logic for intervention. Int. J. Environ. Res. Public Health 6, 2568-2584

9. McNaughton, S. A., Mishra, G. D., Stephen, A. M., and Wadsworth, M. E. (2007) Dietary patterns throughout adult life are associated with body mass index, waist circumference, blood pressure, and red cell folate. J. Nutr. 137, 99-105

10. Qi, L., van Dam, R. M., Liu, S., Franz, M., Mantzoros, C., and Hu, F. B. (2006) Whole-grain, bran, and cereal fiber intakes and markers of systemic inflammation in diabetic women. Diabetes Care 29, 207-211

11. Esmaillzadeh, A., Kimiagar, M., Mehrabi, Y., Azadbakht, L., Hu, F. B., and Willett, W. C. (2007) Dietary patterns, insulin resistance, and prevalence of the metabolic syndrome in women. Am. J. Clin. Nutr. 85, 910-918

12. Wildman, R. P., Muntner, P., Reynolds, K., McGinn, A. P., Rajpathak, S., Wylie-Rosett, J., and Sowers, M. R. (2008) The obese without cardiometabolic risk factor clustering and the normal weight with cardiometabolic risk factor clustering: prevalence and correlates of 2 phenotypes among the US population (NHANES 1999-2004). Arch. Intern. Med. 168, 1617-1624 
13. St-Onge, M. P., Janssen, I., and Heymsfield, S. B. (2004) Metabolic syndrome in normal-weight Americans: new definition of the metabolically obese, normal-weight individual. Diabetes Care 27, 2222-2228

14. Esser, N., Legrand-Poels, S., Piette, J., Scheen, A. J., and Paquot, N. (2014) Inflammation as a link between obesity, metabolic syndrome and type 2 diabetes. Diabetes Res. Clin. Pract. 105, 141-150

15. Matsuda, M., and Shimomura, I. (2014) Roles of adiponectin and oxidative stress in obesity-associated metabolic and cardiovascular diseases. Rev. Endocr. Metab. Disord. 15, 1-10

16. Bremer, A. A., Mietus-Snyder, M., and Lustig, R. H. (2012) Toward a unifying hypothesis of metabolic syndrome. Pediatrics 129, $557-570$

17. Steinberger, J., and Daniels, S. R.; American Heart Association Atherosclerosis, Hypertension, and Obesity in the Young Committee (Council on Cardiovascular Disease in the Young); ; American Heart Association Diabetes Committee (Council on Nutrition, Physical Activity, and Metabolism). (2003) Obesity, insulin resistance, diabetes, and cardiovascular risk in children: an American Heart Association scientific statement from the Atherosclerosis, Hypertension, and Obesity in the Young Committee (Council on Cardiovascular Disease in the Young) and the Diabetes Committee (Council on Nutrition, Physical Activity, and Metabolism). Circulation 107, 1448-1453

18. Pearson, T. A., Mensah, G. A., Alexander, R. W., Anderson, J. L., Cannon III, R. O., Criqui, M., Fadl, Y. Y., Fortmann, S. P., Hong, Y., Myers, G. L., Rifai, N., Smith, Jr., S. C., Taubert, K., Tracy, R. P., and Vinicor, F.; Centers for Disease Control and Prevention; ; American Heart Association. (2003) Markers of inflammation and cardiovascular disease: application to clinical and public health practice: A statement for healthcare professionals from the Centers for Disease Control and Prevention and the American Heart Association. Circulation 107, 499-511

19. National Task Force on the Prevention and Treatment of Obesity. (2000) Overweight, obesity, and health risk. Arch. Intern. Med. 160, 898-904

20. Kalaria, R. N. (2010) Vascular basis for brain degeneration: faltering controls and risk factors for dementia. Nutr. Rev. 68 (Suppl 2), S74-S87

21. Martins, D., Tareen, N., Ogedegbe, G., Pan, D., and Norris, K. (2008) The relative risk of cardiovascular death among racial and ethnic minorities with metabolic syndrome: data from the NHANES-II mortality follow-up. J. Natl. Med. Assoc. 100, 565-571

22. Ludwig, D. S. (2007) Childhood obesity-the shape of things to come. N. Engl. J. Med. 357, 2325-2327

23. Kassirer, J. P., and Angell, M. (1998) Losing weight—an ill-fated New Year's resolution. N. Engl. J. Med. 338, 52-54

24. Weiss, E. C., Galuska, D. A., Kettel Khan, L., Gillespie, C., and Serdula, M. K. (2007) Weight regain in U.S. adults who experienced substantial weight loss, 1999-2002. Am. J. Prev. Med. 33, 34-40

25. Williams, L., Germov, J., and Young, A. (2007) Preventing weight gain: a population cohort study of the nature and effectiveness of mid-age women's weight control practices. Int. J. Obes. (Lond.) 31, 978-986

26. CHRCO/CHORI (2009) Low-calorie nutritional compositions for maintaining metabolic balance. Pending U.S. Application No. 13/877,103; owned by Children's Hospital and Research Center, Oakland, CA, USA

27. Krebs-Smith, S. M., Guenther, P. M., Subar, A. F., Kirkpatrick, S. I., and Dodd, K. W. (2010) Americans do not meet federal dietary recommendations. J. Nutr. 140, 1832-1838

28. Mosfegh, A., Goldman, J., Ahuja, J., Rhodes, D., and LaComb, R. (2009) What we eat in America, NHANES 2005-2006: usual nutrient intakes from food and water compared to 1997 dietary reference intakes for vitamin D, calcium, phosphorus, and magnesium. Available at: http://www.ars.usda.gov/kba/bhnrc/fsrg. Accessed March 27, 2015

29. Ozata, M., Mergen, M., Oktenli, C., Aydin, A., Sanisoglu, S. Y., Bolu, E., Yilmaz, M. I., Sayal, A., Isimer, A., and Ozdemir, I. C. (2002) Increased oxidative stress and hypozincemia in male obesity. Clin. Biochem. 35, 627-631

30. Parikh, S. J., Edelman, M., Uwaifo, G. I., Freedman, R. J., Semega-Janneh, M., Reynolds, J., and Yanovski, J. A. (2004) The relationship between obesity and serum 1,25-dihydroxy vitamin D concentrations in healthy adults. J. Clin. Endocrinol. Metab. 89, 1196-1199
31. Kimmons, J. E., Blanck, H. M., Tohill, B. C., Zhang, J., and Khan, L. K. (2006) Associations between body mass index and the prevalence of low micronutrient levels among US adults. MedGenMed 8, 59

32. Basaki, M., Saeb, M., Nazifi, S., and Shamsaei, H. A. (2012) Zinc, copper, iron, and chromium concentrations in young patients with type 2 diabetes mellitus. Biol. Trace Elem. Res. 148, 161-164

33. Aasheim, E. T., Hofsø, D., Hjelmesaeth, J., Birkeland, K. I., and Bøhmer, T. (2008) Vitamin status in morbidly obese patients: a cross-sectional study. Am. J. Clin. Nutr. 87, 362-369

34. Ames, B. N. (2006) Low micronutrient intake may accelerate the degenerative diseases of aging through allocation of scarce micronutrients by triage. Proc. Natl. Acad. Sci. USA 103, 17589-17594

35. Ames, B. N. (2010) Prevention of mutation, cancer, and other ageassociated diseases by optimizing micronutrient intake. J. Nucleic Acids 2010, 725071

36. McCann, J. C., and Ames, B. N. (2009) Vitamin K, an example of triage theory: is micronutrient inadequacy linked to diseases of aging? Am. J. Clin. Nutr. 90, 889-907

37. McCann, J. C., and Ames, B. N. (2011) Adaptive dysfunction of selenoproteins from the perspective of the triage theory: why modest selenium deficiency may increase risk of diseases of aging. FASEB J. 25, 1793-1814

38. Kranz, S., Brauchla, M., Slavin, J. L., and Miller, K. B. (2012) What do we know about dietary fiber intake in children and health? The effects of fiber intake on constipation, obesity, and diabetes in children. Adv. Nutr. 3, 47-53

39. Anderson, J. W., Baird, P., Davis, Jr., R. H., Ferreri, S., Knudtson, M., Koraym, A., Waters, V., and Williams, C. L. (2009) Health benefits of dietary fiber. Nutr. Rev. 67, 188-205

40. Chen, H. M., Yu, Y. N., Wang, J. L., Lin, Y. W., Kong, X., Yang, C. Q., Yang, L., Liu, Z. J., Yuan, Y. Z., Liu, F., Wu, J. X., Zhong, L., Fang, D. C., Zou, W., and Fang, J. Y. (2013) Decreased dietary fiber intake and structural alteration of gut microbiota in patients with advanced colorectal adenoma. Am.J. Clin. Nutr. 97, 1044-1052

41. Elamin, E. E., Masclee, A. A., Dekker, J., Pieters, H. J., and Jonkers, D. M. (2013) Short-chain fatty acids activate AMP-activated protein kinase and ameliorate ethanol-induced intestinal barrier dysfunction in Caco-2 cell monolayers. J. Nutr. 143, 1872-1881

42. Lewis, K., Lutgendorff, F., Phan, V., Söderholm, J. D., Sherman, P. M., and McKay, D. M. (2010) Enhanced translocation of bacteria across metabolically stressed epithelia is reduced by butyrate. Inflamm. Bowel Dis. 16, 1138-1148

43. Alpers, D. H. (2000) Is glutamine a unique fuel for small intestinal cells? Curr. Opin. Gastroenterol. 16, 155

44. Peng, Z., Ban, K., Wawrose, R. A., Gover, A. G., and Kozar, R. A. (2014) Protection by enteral glutamine is mediated by intestinal epithelial cell peroxisome proliferator-activated receptor gamma during intestinal ischemia/reperfusion PPAR $\gamma$ mediates protection by glutamine. [E-pub ahead of print] Shock 10.1097/SHK. 0000000000000297

45. Beaufrère, A. M., Neveux, N., Patureau Mirand, P., Buffière, C. Marceau, G., Sapin, V., Cynober, L., and Meydinal-Denis, D. (2014) Long-term intermittent glutamine supplementation repairs intestinal damage (structure and functional mass) with advanced age: assessment with plasma citrulline in a rodent model. J. Nutr. Health Aging 18, 814-819

46. Arts, I. C., and Hollman, P. C. (2005) Polyphenols and disease risk in epidemiologic studies. Am. J. Clin. Nutr. 81 (1, Suppl)317S-325S

47. Del Rio, D., Rodriguez-Mateos, A., Spencer, J. P., Tognolini, M., Borges, G., and Crozier, A. (2013) Dietary (poly)phenolics in human health: structures, bioavailability, and evidence of protective effects against chronic diseases. Antioxid. Redox Signal. 18, 1818-1892

48. Queipo-Ortuño, M. I., Boto-Ordóñez, M., Murri, M., Gomez-Zumaquero, J. M., Clemente-Postigo, M., Estruch, R., Cardona Diaz, F., Andrés-Lacueva, C., and Tinahones, F. J. (2012) Influence of red wine polyphenols and ethanol on the gut microbiota ecology and biochemical biomarkers. Am. J. Clin. Nutr. 95, 1323-1334

49. Van Duynhoven, J., Vaughan, E. E., van Dorsten, F., Gomez-Roldan, V., de Vos, R., Vervoort, J., van der Hooft, J. J., Roger, L., Draijer, R., and Jacobs, D. M. (2013) Interactions of black tea polyphenols with human gut microbiota: implications for gut and cardiovascular health. Am. J. Clin. Nutr. 98 (6, Suppl) 1631S-1641S 
50. Kris-Etherton, P. M., Harris, W. S., and Appel, L. J.; Nutrition Committee. (2003) Fish consumption, fish oil, omega-3 fatty acids, and cardiovascular disease. Arterioscler. Thromb. Vasc. Biol. 23, e20-e30

51. Mietus-Snyder, M. L., Shigenaga, M. K., Suh, J. H., Shenvi, S. V., Lal, A., McHugh, T., Olson, D., Lilienstein, J., Krauss, R. M., Gildengoren, G., McCann, J. C., and Ames, B. N. (2012) A nutrientdense, high-fiber, fruit-based supplement bar increases HDL cholesterol, particularly large HDL, lowers homocysteine, and raises glutathione in a 2-wk trial. FASEB J. 26, 3515-3527

52. Asztalos, B. F., Cupples, L. A., Demissie, S., Horvath, K. V., Cox, C. E., Batista, M. C., and Schaefer, E. J. (2004) High-density lipoprotein subpopulation profile and coronary heart disease prevalence in male participants of the Framingham Offspring Study. Arterioscler. Thromb. Vasc. Biol. 24, 2181-2187

53. Musunuru, K., Orho-Melander, M., Caulfield, M. P., Li, S., Salameh, W. A., Reitz, R. E., Berglund, G., Hedblad, B., Engström, G., Williams, P. T., Kathiresan, S., Melander, O., and Krauss, R. M. (2009) Ion mobility analysis of lipoprotein subfractions identifies three independent axes of cardiovascular risk. Arterioscler. Thromb. Vasc. Biol. 29, 1975-1980

54. Hellerstein, M., and Turner, S. (2014) Reverse cholesterol transport fluxes. Curr. Opin. Lipidol. 25, 40-47

55. Novotný, D., Vaverková, H., and Karásek, D. (2012) Adiponectin: a perspective adipose tissue marker with antiinflammatory and antiaterogenic potencial. In Lipoproteins: Role in Health and Disease, pp. 677-700, InTech, Rijeka, Croatia

56. Uhlar, C. M., and Whitehead, A. S. (1999) Serum amyloid A, the major vertebrate acute-phase reactant. Eur. J. Biochem. 265, 501-523

57. Maki, K. C., Carson, M. L., Kerr Anderson, W. H., Geohas, J., Reeves, M. S., Farmer, M. V., Turowski, M., Miller, M., Kaden, V. N., Dicklin, M. R., and Rains, T. M. (2009) Lipid-altering effects of different formulations of hydroxypropylmethylcellulose. J. Clin. Lipidol. 3, 159-166

58. U.S. Department of Agriculture, Agricultural Research Service. (2011) USDA National Nutrient Database for Standard Reference, Release 24. Nutrient Data Laboratory Home Page. Available at: http://www.ars.usda.gov/ba/bhnrc/ndl. Accessed March 27,2015

59. U.S. Department of Agriculture, National Agricultural Library. (2007) USDA Database for the Flavonoid Content of Selected Foods, Release 2.1. Available at: http://www.nal.usda.gov/fnic/ foodcom/Data/Flav/Flav02-1.pdf. Accessed October 9, 2014.

60. Myers, G. L., Rifai, N., Tracy, R. P., Roberts, W. L., Alexander, R. W., Biasucci, L. M., Catravas, J. D., Cole, T. G., Cooper, G. R., Khan, B. V., Kimberly, M. M., Stein, E. A., Taubert, K. A., Warnick, G. R., and Waymack, P. P.; CDC; AHA. (2004) CDC/AHA workshop on markers of inflammation and cardiovascular disease: application to clinical and public health practice: report from the laboratory science discussion group. Circulation 110, e545-e549

61. Friedewald, W. T., Levy, R. I., and Fredrickson, D. S. (1972) Estimation of the concentration of low-density lipoprotein cholesterol in plasma, without use of the preparative ultracentrifuge. Clin. Chem. 18, 499-502

62. Caulfield, M. P., Li, S., Lee, G., Blanche, P. J., Salameh, W. A., Benner, W. H., Reitz, R. E., and Krauss, R. M. (2008) Direct determination of lipoprotein particle sizes and concentrations by ion mobility analysis. Clin. Chem. 54, 1307-1316

63. Graham, T. E., Yang, Q., Blüher, M., Hammarstedt, A., Ciaraldi, T. P., Henry, R. R., Wason, C. J., Oberbach, A., Jansson, P. A., Smith, U., and Kahn, B. B. (2006) Retinol-binding protein 4 and insulin resistance in lean, obese, and diabetic subjects. N. Engl.J. Med. 354, 2552-2563

64. Ghosh, A. (2007) Comparison of anthropometric, metabolic and dietary fatty acids profiles in lean and obese dyslipidaemic Asian Indian male subjects. Eur. J. Clin. Nutr. 61, 412-419

65. Ghosh, A. (2007) Anthropometric, metabolic, and dietary fatty acids characteristics in lean and obese dyslipidemic Asian Indian women in Calcutta. Food Nutr. Bull. 28, 399-405

66. Mietus-Snyder, M., Drews, K. L., Otvos, J. D., Willi, S. M., Foster, G. D., Jago, R., and Buse, J. B.; HEALTHYStudy Group. (2013) Lowdensity lipoprotein cholesterol versus particle number in middle school children. J. Pediatr. 163, 355-362

67. Bioletto, S., Golay, A., Munger, R., Kalix, B., and James, R. W. (2000) Acute hyperinsulinemia and very-low-density and lowdensity lipoprotein subfractions in obese subjects. Am. J. Clin. Nutr. 71, 443-449
68. Rosenson, R. S., Brewer, Jr., H. B., Ansell, B., Barter, P., Chapman, M. J., Heinecke, J. W., Kontush, A., Tall, A. R., and Webb, N. R. (2013) Translation of high-density lipoprotein function into clinical practice: current prospects and future challenges. Circulation 128, 1256-1267

69. Falcão-Pires, I., Castro-Chaves, P., Miranda-Silva, D., Lourenço, A. P., and Leite-Moreira, A. F. (2012) Physiological, pathological and potential therapeutic roles of adipokines. Drug Discov. Today 17 , 880-889

70. King, V. L., Thompson, J., and Tannock, L. R. (2011) Serum amyloid A in atherosclerosis. Curr. Opin. Lipidol. 22, 302-307

71. Krauss, R. M. (2014) All low-density lipoprotein particles are not created equal. Arterioscler. Thromb. Vasc. Biol. 34, 959-961

72. Williams, P. T., Zhao, X. Q., Marcovina, S. M., Otvos, J. D., Brown, B. G., and Krauss, R. M. (2014) Comparison of four methods of analysis of lipoprotein particle subfractions for their association with angiographic progression of coronary artery disease. Atherosclerosis 233, 713-720

73. Kishida, K., Funahashi, T., and Shimomura, I. (2014) Adiponectin as a routine clinical biomarker. Best Pract. Res. Clin. Endocrinol. Metab. 28, 119-130

74. Blackburn, R., Giral, P., Bruckert, E., André, J. M., Gonbert, S., Bernard, M., Chapman, M. J., and Turpin, G. (2001) Elevated Creactive protein constitutes an independent predictor of advanced carotid plaques in dyslipidemic subjects. Arterioscler. Thromb. Vasc. Biol. 21, 1962-1968

75. St-Onge, M. P., Zhang, S., Darnell, B., and Allison, D. B. (2009) Baseline serum C-reactive protein is associated with lipid responses to low-fat and high-polyunsaturated fat diets. J. Nutr. 139, 680-683

76. Desroches, S., Archer, W. R., Paradis, M. E., Dériaz, O., Couture, P. Bergeron, J., Bergeron, N., and Lamarche, B. (2006) Baseline plasma C-reactive protein concentrations influence lipid and lipoprotein responses to low-fat and high monounsaturated fatty acid diets in healthy men. J. Nutr. 136, 1005-1011

77. Erlinger, T. P., Miller III, E. R., Charleston, J., and Appel, L. J. (2003) Inflammation modifies the effects of a reduced-fat low-cholesterol diet on lipids: results from the DASH-sodium trial. Circulation $\mathbf{1 0 8}$, 150-154

78. Hilpert, K. F., Kris-Etherton, P. M., and West, S. G. (2005) Lipid response to a low-fat diet with or without soy is modified by $\mathrm{C}$ reactive protein status in moderately hypercholesterolemic adults. J. Nutr. 135, 1075-1079

79. Gigleux, I., Jenkins, D. J., Kendall, C. W., Marchie, A., Faulkner, D. A., Wong, J. M., de Souza, R., Emam, A., Parker, T. L., Trautwein, E. A., Lapsley, K. G., Connelly, P. W., and Lamarche, B. (2007) Comparison of a dietary portfolio diet of cholesterol-lowering foods and a statin on LDL particle size phenotype in hypercholesterolaemic participants. Br. J. Nutr. 98, 1229-1236

80. Kong, L. C., Wuillemin, P. H., Bastard, J. P., Sokolovska, N., Gougis, S., Fellahi, S., Darakhshan, F., Bonnefont-Rousselot, D., Bittar, R., Doré, J., Zucker, J. D., Clément, K., and Rizkalla, S. (2013) Insulin resistance and inflammation predict kinetic body weight changes in response to dietary weight loss and maintenance in overweight and obese subjects by using a Bayesian network approach. Am. J. Clin. Nutr. 98, 1385-1394

81. Chan, D. C., Barrett, P. H., and Watts, G. F. (2014) The metabolic and pharmacologic bases for treating atherogenic dyslipidaemis. Best Pract. Res. Clin. Endocrinol. Metab. 28, 369-385

82. Christou, G. A., and Kiortsis, D. N. (2013) Adiponectin and lipoprotein metabolism. Obes. Rev. 14, 939-949

83. Lim, S., Quon, M. J., and Koh, K. K. (2014) Modulation of adiponectin as a potential therapeutic strategy. Atherosclerosis $\mathbf{2 3 3}$, 721-728

84. Manco, M., Putignani, L., and Bottazzo, G. F. (2010) Gut microbiota, lipopolysaccharides, and innate immunity in the pathogenesis of obesity and cardiovascular risk. Endocr. Rev. 31, 817-844

85. Fernández-Sánchez, A., Madrigal-Santillán, E., Bautista, M., Esquivel-Soto, J., Morales-González, A., Esquivel-Chirino, C., Durante-Montiel, I., Sánchez-Rivera, G., Valadez-Vega, C., and Morales-González, J. A. (2011) Inflammation, oxidative stress, and obesity. Int. J. Mol. Sci. 12, 3117-3132

86. Harte, A. L., Varma, M. C., Tripathi, G., McGee, K. C., Al-Daghri, N. M., Al-Attas, O. S., Sabico, S., O’Hare, J. P., Ceriello, A., Saravanan, P., Kumar, S., and McTernan, P. G. (2012) High fat 
intake leads to acute postprandial exposure to circulating endotoxin in type 2 diabetic subjects. Diabetes Care 35, 375-382

87. Yuzefovych, L. V., Musiyenko, S. I., Wilson, G. L., and Rachek, L. I. (2013) Mitochondrial DNA damage and dysfunction, and oxidative stress are associated with endoplasmic reticulum stress, protein degradation and apoptosis in high fat diet-induced insulin resistance mice. PLoS One 8, e54059

88. Piya, M. K., McTernan, P. G., and Kumar, S. (2013) Adipokine inflammation and insulin resistance: the role of glucose, lipids and endotoxin. J. Endocrinol. 216, T1-T15

89. Hu, F., and Liu, F. (2011) Mitochondrial stress: a bridge between mitochondrial dysfunction and metabolic diseases? Cell. Signal. 23, 1528-1533

90. Munsters, M. J., and Saris, W. H. (2014) Body weight regulation and obesity: dietary strategies to improve the metabolic profile. Annu. Rev. Food Sci. Technol. 5, 39-51

91. Toledo, F. G., and Goodpaster, B. H. (2013) The role of weight loss and exercise in correcting skeletal muscle mitochondrial abnormalities in obesity, diabetes and aging. Mol. Cell. Endocrinol. 379, 30-34

92. Liesa, M., and Shirihai, O. S. (2013) Mitochondrial dynamics in the regulation of nutrient utilization and energy expenditure. Cell Metab. 17, 491-506

93. Fisher-Wellman, K. H., and Neufer, P. D. (2012) Linking mitochondrial bioenergetics to insulin resistance via redox biology. Trends Endocrinol. Metab. 23, 142-153

94. Yan, L. J. (2014) Pathogenesis of chronic hyperglycemia: from reductive stress to oxidative stress. J. Diabetes Res. 2014, 137919

95. Vial, G., Dubouchaud, H., Couturier, K., Cottet-Rousselle, C., Taleux, N., Athias, A., Galinier, A., Casteilla, L., and Leverve, X. M. (2011) Effects of a high-fat diet on energy metabolism and ROS production in rat liver. J. Hepatol. 54, 348-356

96. Henriksen, E. J., Diamond-Stanic, M. K., and Marchionne, E. M. (2011) Oxidative stress and the etiology of insulin resistance and type 2 diabetes. Free Radic. Biol. Med. 51, 993-999

97. Bashan, N., Kovsan, J., Kachko, I., Ovadia, H., and Rudich, A. (2009) Positive and negative regulation of insulin signaling by reactive oxygen and nitrogen species. Physiol. Rev. 89, 27-71

98. Houstis, N., Rosen, E. D., and Lander, E. S. (2006) Reactive oxygen species have a causal role in multiple forms of insulin resistance. Nature 440, 944-948

99. Lipina, C., Macrae, K., Suhm, T., Weigert, C., Blachnio-Zabielska, A., Baranowski, M., Gorski, J., Burgess, K., and Hundal, H. S. (2013) Mitochondrial substrate availability and its role in lipid-induced insulin resistance and proinflammatory signaling in skeletal muscle. Diabetes 62, 3426-3436

100. Savage, D. B., Petersen, K. F., and Shulman, G. I. (2005) Mechanisms of insulin resistance in humans and possible links with inflammation. Hypertension 45, 828-833

101. Maki, K. C., Carson, M. L., Miller, M. P., Turowski, M., Bell, M., Wilder, D. M., and Reeves, M. S. (2007) High-viscosity hydroxypropylmethylcellulose blunts postprandial glucose and insulin responses. Diabetes Care 30, 1039-1043

102. Brockman, D. A., Chen, X., and Gallaher, D. D. (2014) Highviscosity dietary fibers reduce adiposity and decrease hepatic steatosis in rats fed a high-fat diet. J. Nutr. 144, 1415-1422

103. Kelley, D. S., Siegel, D., Vemuri, M., and Mackey, B. E. (2007) Docosahexaenoic acid supplementation improves fasting and postprandial lipid profiles in hypertriglyceridemic men. Am. J. Clin. Nutr. 86, 324-333

104. Most, J., Goossens, G. H., Jocken, J. W., and Blaak, E. E. (2014) Short-term supplementation with a specific combination of dietary polyphenols increases energy expenditure and alters substrate metabolism in overweight subjects. Int. J. Obes. (Lond.) 38, 698-706

105. Chuang, C. C., and McIntosh, M. K. (2011) Potential mechanisms by which polyphenol-rich grapes prevent obesitymediated inflammation and metabolic diseases. Annu. Rev. Nutr. 31, 155-176

106. Cani, P. D., Amar, J., Iglesias, M. A., Poggi, M., Knauf, C., Bastelica, D., Neyrinck, A. M., Fava, F., Tuohy, K. M., Chabo, C., Waget, A., Delmée, E., Cousin, B., Sulpice, T., Chamontin, B., Ferrières, J., Tanti,J. F., Gibson, G. R., Casteilla, L., Delzenne, N. M., Alessi, M. C., and Burcelin, R. (2007) Metabolic endotoxemia initiates obesity and insulin resistance. Diabetes 56, 1761-1772
107. Thuy, S., Ladurner, R., Volynets, V., Wagner, S., Strahl, S., Königsrainer, A., Maier, K. P., Bischoff, S. C., and Bergheim, I. (2008) Nonalcoholic fatty liver disease in humans is associated with increased plasma endotoxin and plasminogen activator inhibitor 1 concentrations and with fructose intake. J. Nutr. 138, $1452-1455$

108. Jin, R., Willment, A., Patel, S. S., Sun, X., Song, M., Mannery, Y. O., Kosters, A., McClain, C. J., and Vos, M. B. (2014) Fructose induced endotoxemia in pediatric nonalcoholic Fatty liver disease. Int. J. Hepatol. 2014, 560620

109. dos Santos, Rd., Viana, M. L., Generoso, S. V., Arantes, R. E., Davisson Correia, M. I., and Cardoso, V. N. (2010) Glutamine supplementation decreases intestinal permeability and preserves gut mucosa integrity in an experimental mouse model. JPEN J. Parenter. Enteral Nutr. 34, 408-413

110. Spaeth, G., Gottwald, T., and Hirner, A. (1995) Fibre is an essential ingredient of enteral diets to limit bacterial translocation in rats. Eur. J. Surg. 161, 513-518

111. Mosenthal, A. C., Xu, D., and Deitch, E. A. (2002) Elemental and intravenous total parenteral nutrition diet-induced gut barrier failure is intestinal site specific and can be prevented by feeding nonfermentable fiber. Crit. Care Med. 30, 396-402

112. Camilleri, M., Madsen, K., Spiller, R., Greenwood-Van Meerveld, B., and Verne, G. N. (2012) Intestinal barrier function in health and gastrointestinal disease. Neurogastroenterol. Motil. 24, 503512

113. Turner, J. R. (2009) Intestinal mucosal barrier function in health and disease. Nat. Rev. Immunol. 9, 799-809

114. Guarner, F., and Malagelada, J. R. (2003) Gut flora in health and disease. Lancet 361, 512-519

115. van Diepen, J. A., Berbée, J. F., Havekes, L. M., and Rensen, P. C. (2013) Interactions between inflammation and lipid metabolism: relevance for efficacy of anti-inflammatory drugs in the treatment of atherosclerosis. Atherosclerosis 228, 306-315

116. Baker, B., Maitra, U., Geng, S., and Li, L. (2014) Molecular and cellular mechanisms responsible for cellular stress and low-grade inflammation induced by a super-low dose of endotoxin. J. Biol. Chem. 289, 16262-16269

117. Glaros, T. G., Chang, S., Gilliam, E. A., Maitra, U., Deng, H., and $\mathrm{Li}, \mathrm{L}$. (2013) Causes and consequences of low grade endotoxemia and inflammatory diseases. Front. Biosci. (Schol. Ed.) 5, 754-765

118. Wu, G. H., Wang, H., Zhang, Y. W., Wu, Z. H., and Wu, Z. G. (2004) Glutamine supplemented parenteral nutrition prevents intestinal ischemia- reperfusion injury in rats. World J. Gastroenterol. 10, 25922594

119. Lambert, J. C., Zhou, Z., Wang, L., Song, Z., McClain, C. J., and Kang, Y. J. (2003) Prevention of alterations in intestinal permeability is involved in zinc inhibition of acute ethanolinduced liver damage in mice. J. Pharmacol. Exp. Ther. 305, 880-886

120. Sturniolo, G. C., Fries, W., Mazzon, E., Di Leo, V., Barollo, M., and D'inca, R. (2002) Effect of zinc supplementation on intestinal permeability in experimental colitis. J. Lab. Clin. Med. 139, 311-315

121. Zhong, W., McClain, C. J., Cave, M., Kang, Y. J., and Zhou, Z. (2010) The role of zinc deficiency in alcohol-induced intestinal barrier dysfunction. Am. J. Physiol. Gastrointest. Liver Physiol. 298 , G625-G633

122. Swaid, F., Sukhotnik, I., Matter, I., Berkowitz, D., Hadjittofi, C., Pollak, Y., and Lavy, A. (2013) Dietary glutamine supplementation prevents mucosal injury and modulates intestinal epithelial restitution following acetic acid induced intestinal injury in rats. Nutr. Metab. (Lond.) 10, 53

123. Cani, P. D., and Delzenne, N. M. (2009) The role of the gut microbiota in energy metabolism and metabolic disease. Curr. Pharm. Des. 15, 1546-1558

124. Cornell, R. P. (1985) Endogenous gut-derived bacterial endotoxin tonically primes pancreatic secretion of insulin in normal rats. $D i$ abetes 34, 1253-1259

125. Grunfeld, C., Zhao, C., Fuller, J., Pollack, A., Moser, A., Friedman, J., and Feingold, K. R. (1996) Endotoxin and cytokines induce expression of leptin, the ob gene product, in hamsters. J. Clin. Invest. 97, 2152-2157

126. Reinehr, T. (2013) Lifestyle intervention in childhood obesity: changes and challenges. Nat. Rev. Endocrinol. 9, 607-614 
127. Waters, E., de Silva-Sanigorski, A., Hall, B. J., Brown, T., Campbell, K. J., Gao, Y., Armstrong, R., Prosser, L., and Summerbell, C. D. (2011) Interventions for preventing obesity in children. Cochrane Database Syst. Rev. (12):CD001871

128. Di Daniele, N., Petramala, L., Di Renzo, L., Sarlo, F., Della Rocca, D. G., Rizzo, M., Fondacaro, V., Iacopino, L., Pepine, C. J., and De Lorenzo, A. (2013) Body composition changes and cardiometabolic benefits of a balanced Italian mediterranean diet in obese patients with metabolic syndrome. Acta Diabetol. 50, 409-416

129. Sabin, M. A., Ford, A., Hunt, L., Jamal, R., Crowne, E. C., and Shield, J. P. (2007) Which factors are associated with a successful outcome in a weight management programme for obese children? J. Eval. Clin. Pract. 13, 364-368

130. Reinehr, T. (2011) Effectiveness of lifestyle intervention in overweight children. Proc. Nutr. Soc. 70, 494-505

131. Alhassan, S., Kim, S., Bersamin, A., King, A. C., and Gardner, C. D. (2008) Dietary adherence and weight loss success among overweight women: results from the A TO $\mathrm{Z}$ weight loss study. Int. J. Obes. (Lond.) 32, 985-991

132. Wadden, T. A., Volger, S., Tsai, A. G., Sarwer, D. B., Berkowitz, R. I. Diewald, L. K., Carvajal, R., Moran, C. H., and Vetter, M.; POWERUP Research Group. (2013) Managing obesity in primary care practice: an overview with perspective from the POWER-UP study. Int. J. Obes. (Lond.) 37 (Suppl 1), S3-S11

133. Stone, N. J., Robinson, J. G., Lichtenstein, A. H., Goff, Jr., D. C., Lloyd-Jones, D. M., Smith, Jr., S. C., Blum, C., and Schwartz, J. S.;
2013 ACC/AHA Cholesterol Guideline Panel. (2014) Treatment of blood cholesterol to reduce atherosclerotic cardiovascular disease risk in adults: synopsis of the 2013 American College of Cardiology/ American Heart Association cholesterol guideline. Ann. Intern. Med. 160, 339-343

134. Wilkinson, M. J., Laffin, L. J., and Davidson, M. H. (2014) Overcoming toxicity and side-effects of lipid-lowering therapies. Best Pract. Res. Clin. Endocrinol. Metab. 28, 439-452

135. Sarafidis, P.A. (2008) Thiazolidinedione derivatives in diabetes and cardiovascular disease: an update. Fundam. Clin. Pharmacol. 22, 247-264

136. Pernicova, I., and Korbonits, M. (2014) Metformin-mode of action and clinical implications for diabetes and cancer. Nat. Rev. Endocrinol. 10, 143-156

137. Iyer, A., Fairlie, D. P., Prins, J. B., Hammock, B. D., and Brown, L. (2010) Inflammatory lipid mediators in adipocyte function and obesity. Nat. Rev. Endocrinol. 6, 71-82

138. Bouchoucha, M., Uzzan, B., and Cohen, R. (2011) Metformin and digestive disorders. Diabetes Metab. 37, 90-96

139. Zeino, Z., Sisson, G., and Bjarnason, I. (2010) Adverse effects of drugs on small intestine and colon. Best Pract. Res. Clin. Gastroenterol. 24, 133-141

140. Heaney, R. P. (2006) Nutrition, chronic disease, and the problem of proof. Am. J. Clin. Nutr. 84, 471-472

Received for publication February 24, 2015. Accepted for publication March 31, 2015. 